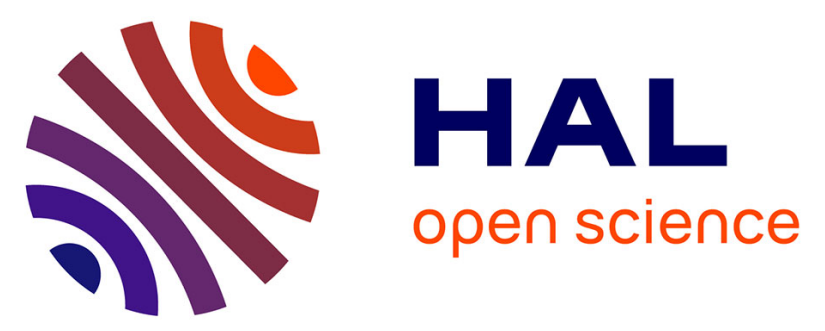

\title{
The averaged potential gradient approach to model the rejection of electrolyte solutions using nanofiltration: Model development and assessment for highly concentrated feed solutions
}

\author{
Karim Thibault, Haochen Zhu, Anthony Szymczyk, Guangming Li
}

\section{To cite this version:}

Karim Thibault, Haochen Zhu, Anthony Szymczyk, Guangming Li. The averaged potential gradient approach to model the rejection of electrolyte solutions using nanofiltration: Model development and assessment for highly concentrated feed solutions. Separation and Purification Technology, 2015, 153, pp.126-137. 10.1016/j.seppur.2015.08.041 . hal-01240648

HAL Id: hal-01240648

https://hal-univ-rennes1.archives-ouvertes.fr/hal-01240648

Submitted on 27 Jan 2016

HAL is a multi-disciplinary open access archive for the deposit and dissemination of scientific research documents, whether they are published or not. The documents may come from teaching and research institutions in France or abroad, or from public or private research centers.
L'archive ouverte pluridisciplinaire HAL, est destinée au dépôt et à la diffusion de documents scientifiques de niveau recherche, publiés ou non, émanant des établissements d'enseignement et de recherche français ou étrangers, des laboratoires publics ou privés. 


\title{
THE AVERAGED POTENTIAL GRADIENT
}

\author{
APPROACH TO MODEL THE REJECTION OF
}

\author{
ELECTROLYTE SOLUTIONS USING
}

NANOFILTRATION: MODEL DEVELOPMENT

\section{AND ASSESSMENT FOR HIGHLY \\ CONCENTRATED FEED SOLUTIONS}

Karim Thibault ${ }^{1}$, Haochen Zhu ${ }^{1, *}$, Anthony Szymczyk ${ }^{2}$, Guangming $L i^{1}$

${ }^{1}$ State Key Laboratory of Pollution Control and Resources Reuse, College of Environmental

Science and Engineering, Tongji University, 1239 Siping Rd., Shanghai, 200092, China

${ }^{2}$ Université de Rennes 1, Institut des Sciences Chimiques de Rennes-UMR 6226 CNRS, 263 av. du général Leclerc, 35042 Rennes Cedex, France

* Corresponding author, haochen_zhu@tongji.edu.cn

\section{Abstract}

Some of the recent publications in nanofiltration modelling converge on the importance of dielectric effects and numerous models have been developed in order to take them into account. However several works reported lately in the literature suggest a screening of image 
charges effect at high electrolyte concentration and the predominance of the Born effect, due to the change of dielectric constant inside the confined nanopore regarding that of the feed solution. In pursuit of an exhaustive and simple model for nanofiltration, a new approach is developed that account for both dielectric phenomena. Based on the Steric, Electric and Dielectric Exclusion (SEDE), the introduction of an average potential gradient approximation is shown to greatly improve the computational performance of the model without being detrimental to its predictive accuracy. The results obtained with this simplified model (SEDEAPG) are compared to the original SEDE model and an excellent agreement is obtained even in the case of electrolyte mixtures. Ultimately this model is confronted to experimental data of separation obtained for moderately to highly concentrated feed flows and exhibits promising results.

Keywords: nanofiltration; SEDE model; high concentration; average potential approach; dielectric effects

\section{Introduction}

Since 1970 s, the field of pressure-driven separation techniques has been push forward by the increasing exigencies of efficiency, prevailing as a cheap, sustainable and reliable solution for separation or concentration operations [1]. The growing need for a technology coupling the high retention rate of reverse osmosis (RO) with the moderate pressure difference used in ultrafiltration (UF) led to the development of nanofiltration (NF), a promising technique which already found applications at industrial scales [2].

The majority of the nanofiltration membranes are polyamide thin-film composite (TFC) [3]. The preparation of those membranes is mainly operated through interfacial polymerisation (IP) on an appropriate microporous support, which is fixed on a woven or non- woven reinforcing layer. The IP is usually realised by in-situ polycondensation on the microporous support [4]. 
Hence, several factors, inherent to the operating conditions, as well as the choice of the microporous support [5-7], are likely to affect the physic-chemical properties of the active layer. Therefore, the issue of characterisation of the polyamide layer has been addressed in several publications $[5,8-11]$ in order to improve the understanding of the selectivity and permeability processes through this layer.

Even though the rejection of ions can be convincingly modelled by a simple Donnan equilibrium approach in the case monovalent ion solution [12] or for sufficiently large pore [13], the high selectivity regarding multivalent ions, typically observed in the pore range of nanofiltration [14], remains poorly explained by this traditional approach which often relies in inconsistent fitting values for charge densities $[15,16]$ or thickness over porosity ratio [17-19]. A convincing way to address these shortcomings could be to introduce the influence of dielectric effects. The impact of dielectric effect in ion exchange membranes has been firstly stressed by Glueckauf [20] before being roughly considered by Fane et al. [21] and further reviewed and analysed by Yaroshchuk [22], who pointed out its potential importance, as well as the difficulty to quantify its actual contribution. Later, the development of the DSPM\&DE model by Vezzani and Bandini [14,23], on the basis of the DSPM model introduced by Bowen and co-workers [16,17,24,25], allowed to take into account the dielectric exclusion resulting from the difference between the dielectric constant of the membrane matrix and the one of the solution - considered as unique in the bulk and inside the confined nanopores. More recently, by developing a steric, electric and dielectric exclusion (SEDE) model, Szymczyk and Fievet added a stone to the edifice of dielectric effects modelling in nanofiltration processes [26]. It notably includes, in a coherent framework, both the exclusion resulting from the difference of dielectric constant between the bulk and the solution confined in the nanopores - the so-called Born effect - , and the one resulting from 
the difference between the dielectric constant of the membrane matrix and of the electrolyte solution - the so-called image effect.

If the influence of the latter has already been submitted to specific theoretical investigations $[22,27]$, the former, namely Born effect, has recently drawn more attention owing to the simplicity of its computation and its ability to accurately render specific behaviours observed in nanofiltration, and notably the high selectivity regarding multivalent ions. The works of Oatley et al. and, before, that of Bowen \& Welfoot have been introducing a two parameter model assuming Born partition to be the only dielectric phenomenon involved at the pore interfaces [16,28-31]. Their approach, involving the study of rejection at the isoelectric point of the membrane and the assumption of screened image forces at high charge densities, has shown to be successful. However this latter assumption is only backed by qualitative considerations, and is all the more questionable as the charge of the membrane is compensated at the point of zero charge.

As a matter of fact, recent computer experiment confirmed the effect of nanoconfinment on the dielectric constant of water and aqueous solutions [32-35]. At the same time, the extensive studies carried out on the theoretical influence of image charges clearly stress their theoretical significance $[22,26,27,36]$ and some experimental results also point towards the importance of taking the low dielectric constant of the membrane matrix into account [37]. Although the overlapping between dielectric and electrostatic effects makes it difficult to accurately assess the share of each in the rejection process, it is herein acknowledge that, $a$ priori, the rejection mechanism is a conjunction of steric, electrostatic and dielectric effects.

Recognizing the need for a tool equally simple and exhaustive for NF modelling, this work explores a simplified approach to assess the actual rejection of electrolyte solutions considering the influence of dielectric effects. First, by considering the rejection of 
electrolytes through homogeneously charged membranes, it is shown, through a study of the electric field along the pore, that it is possible to linearly approximate the potential gradient. Consequently, a simplified model is deduced (SEDE-APG for Averaged Potential Gradient) and compared to the original SEDE model. The results obtained with the former show excellent agreement with those provided by the original model. Moreover it proves to be less resource consuming and faster in terms of computation. Ultimately this simplified model is confronted to experimental data from the literature in order to critically discuss the theoretical contribution of dielectric effects in nanofiltration prediction.

\section{Theoretical background}

NF membrane is assumed to be a matrix of identical pores, characterised by their half-size $r_{p}$ and their thickness $\Delta z$ as depicted in Fig. 1. The study of concentration polarisation being beyond the scope of this work, the external solution is assumed to be ideal and perfectly stirred, so that this phenomenon can be disregarded throughout the development of the model. The system considered is isothermal at $298 \mathrm{~K}$.

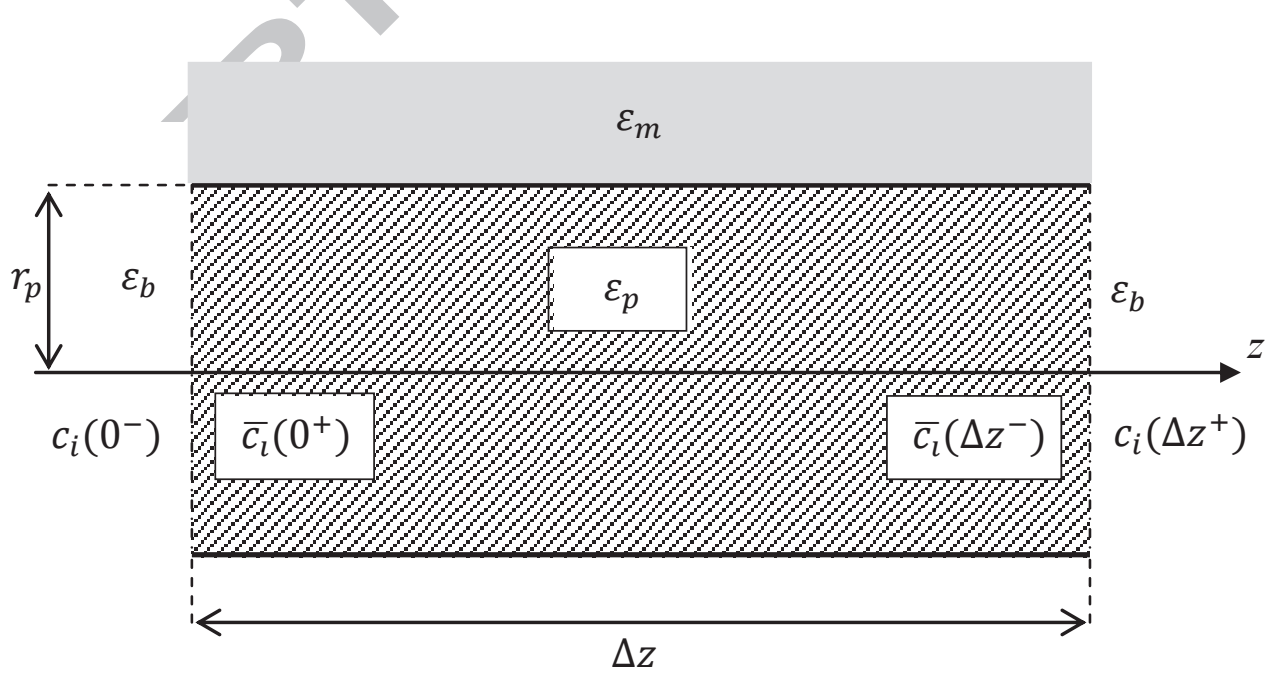

Figure 1. Representation of a pore of radius $r_{p}$ and length $\Delta z . \varepsilon_{b}$ denotes the relative permittivity of the bulk, therefore equal in the permeate and retentate, while $\varepsilon_{p}$ is the relative 
permittivity inside the pore and $\varepsilon_{m}$ that of the membrane material (equal to 3 for polyamide materials [38]). $c_{i}\left(0^{-}\right)$and $c_{i}\left(\Delta z^{+}\right)$respectively denote the bulk concentration at the pore inlet and outlet, while $\overline{c_{l}}\left(0^{+}\right)$and $\overline{c_{l}}\left(\Delta z^{-}\right)$stand for that of the confined solution. The axial coordinate is $z$.

The pressure-driven transport of each ion $i$ of charge $z_{i}$ is investigated through the extended Nernst-Planck (ENP) equation. This one accounts for the diffusion of ions under a concentration gradient, their electromigration inside the pore due to the spontaneous formation of an electric field and their convection throughout the flow inside the membrane. By taking into account the hindrance factors for diffusion and convection, the ENP equation can be adapted to the specific case of a NF membrane [17,18,23,26,28,39-45]. At last, giving the negligible radial variation of the potential inside a pore of nanoscale $[9,41,42,46-48]$, the local ion concentrations and electrostatic potential inside the pore can be radially averaged, leading to a one dimensional approximation of the aforementioned model:

$$
j_{i}=-K_{i, d} D_{i, \infty} \frac{d \bar{c}_{l}(z)}{d z}-\frac{F K_{i, d} z_{i} D_{i, \infty} \overline{c_{l}}(z)}{R T} \frac{d \bar{\psi}(z)}{d z}+K_{i, c} \overline{c_{l}}(z) \frac{J_{v}}{A_{k}}
$$

Where $j_{i}$ is the molar flux density of the ion $i, D_{i, \infty}$ its diffusion coefficient at infinite dilution, $z_{i}$ its charge number, $c_{i}$ its concentration and $K_{i, d}$ and $K_{i, c}$ are respectively the diffusion and convection hindrance factors related to this ion, calculated using the approximate equations derived by Bungay and Brenner [49]. Besides, $F$ stands for the Faraday constant, $R$ for the ideal gas constant, $\psi$ for the electric potential inside the pore while $J_{v}$ represents the permeate volume flux and $A_{k}$ the membrane porosity.

The Poisson equation being dropped in the uniform approximation, it has to be replaced by the explicit electroneutrality condition inside the pores: 


$$
\sum_{i} z_{i} \overline{c_{l}}(z)+X(z)=0 \quad \text { for } 0^{+} \leq z \leq \Delta z^{-}
$$

where $X(z)$ stands for the local volume fixed-charge density inside the pores.

It is worth mentioning that in Eq. (2) the fixed-charge density is considered to be homogeneous. Even though previous theoretical works have stressed the impact of inhomogeneous charge distributions on membrane rejection [46,50-53], this approximation remain a reliable way to predict the behaviour of a wide range of commercial membranes [54].

Considering the following intrinsic filtration condition:

$$
j_{i}=\frac{J_{v} c_{i}\left(\Delta \bar{z}^{+}\right)}{A_{k}}
$$

The ENP equation (1), can be transformed to express the concentration gradient within the nanopore:

$$
\frac{d \overline{c_{l}}(z)}{d z}=\frac{J_{v}}{K_{i, d} D_{i, \infty} A_{k}}\left(K_{i, c} \bar{c}_{l}(z)-c_{i}\left(\Delta z^{+}\right)\right)-\frac{z_{i} F \overline{c_{l}}(z)}{R T} \frac{d \bar{\psi}(z)}{d z}
$$

Combining this latter equation (4) with the electronegativity condition (2), the expression of the electric field inside the membrane can be deduced:

$$
E(z)=-\frac{d \bar{\psi}(z)}{d z}=-\frac{\sum_{i} \frac{z_{i} J_{v}}{K_{i, d} D_{i, \infty} A_{k}}\left(K_{i, c} \bar{c}_{l}(z)-c_{i}\left(\Delta z^{+}\right)\right)}{\frac{F}{R T} \sum_{i} \overline{c_{l}}(z) z_{i}^{2}}-\frac{\frac{d X(z)}{d z}}{\frac{F}{R T} \sum_{i} \overline{c_{l}}(z) z_{i}^{2}}
$$


For the description of the Born effect, the approach used in this work is inspired from the model developed by Born to calculate the electrostatic energy involved in the solvation of a spherical ion characterised by its radius $r_{i}$ and its valence $z_{i}$ [55]. Adapting this result to the transfer of an ion from the bulk (dielectric constant $\varepsilon_{b}$ ) to the confined solution inside the nanopore (dielectric constant $\varepsilon_{p}$ ), the following relation is obtained:

$$
\Delta W_{i, \text { Born }}^{\prime}=\frac{\left(z_{i} q\right)^{2}}{8 \pi \varepsilon_{0} k_{B} T r_{i, c a v}}\left(\frac{1}{\varepsilon_{p}}-\frac{1}{\varepsilon_{b}}\right)
$$

where $\varepsilon_{0}$ is the vacuum permittivity and the prime sign is added to signify that the term is scaled on $k_{B} T, k_{B}$ being the Boltzmann constant and T the operating temperature. Another notable difference with the original Born formula, is the use of the cavity radius, defined as the distance from the centre of the ion where the medium begins, instead of ionic radius, as proposed by Rashin and Honig [56]. The best fitting value for it is obtained by increasing respectively the covalent radius of cations and the ionic radius of anions by $7 \%$ (this might be explained by the phenomenon of dielectric saturation) [26].

It should be noticed that, for the sake of simplicity in this study, two distinct and uniform dielectric constants inside the bulk and the confined nanopore were considered. Although some attempts to account for the variation of the dielectric constant inside the nanopore already exist $[22,28,29,57]$, the available experimental methods are not able to confirm the validity of those models and the recent computer simulation seem to refute them [32-35]. Moreover the unidimensional nature of the current NF models is hardly able to cope with the supposed variations of the constant inside the pore.

The solvation energy due to image forces (denoted $\Delta W_{i, I m}^{\prime}$ ) is accounted for using the model developed by Yaroschuk [22] for slit-like pores: 


$$
\begin{gathered}
\Delta W_{i, I m\left(0^{-} \mid 0^{+}\right)}^{\prime}=-\alpha_{i} \ln \left[1-\left(\frac{\varepsilon_{p}-\varepsilon_{m}}{\varepsilon_{p}+\varepsilon_{m}}\right) e^{\left.-2 \mu_{\left(0^{-} \mid 0^{+}\right)}\right]}\right. \\
\Delta W_{i, I m\left(\Delta z^{-} \mid \Delta z^{+}\right)}^{\prime}=-\alpha_{i} \ln \left[1-\left(\frac{\varepsilon_{p}-\varepsilon_{m}}{\varepsilon_{p}+\varepsilon_{m}}\right) e^{-2 \mu_{\left(\Delta z^{-} \mid \Delta z^{+}\right)}}\right]
\end{gathered}
$$

with:

$$
\begin{gathered}
\mu_{\left(0^{-} \mid 0^{+}\right)}=\left(\frac{\varepsilon_{0} \varepsilon_{b} R T}{2 F^{2} I}\right)^{-1 / 2} r_{p} \sqrt{\sum_{i} \frac{z_{i}^{2} c_{i}\left(0^{-}\right) \Lambda_{i,\left(0^{-} \mid 0^{+}\right)}}{2 I}} \\
\mu_{\left(\Delta z^{-} \mid \Delta z^{+}\right)}=\left(\frac{\varepsilon_{0} \varepsilon_{b} R T}{2 F^{2} I}\right)^{-1 / 2} r_{p} \sqrt{\sum_{i} \frac{z_{i}^{2} c_{i}\left(\Delta z^{+}\right) \Lambda_{i,\left(\Delta z^{-} \mid \Delta z^{+}\right)}}{2 I}} \\
\alpha_{i}=\frac{\left(z_{i} F\right)^{2}}{8 \pi \varepsilon_{0} \varepsilon_{p} R T N_{a} r_{p}}
\end{gathered}
$$

It is worth noticing that the solvation energy model for cylindrical pore could as well be applied. We won't detail it here as it has been extensively described in existing literature $[22,26,27]$. Here $\Lambda_{i,\left(\Delta z^{-} \mid \Delta z^{+}\right)}$and $\Lambda_{i,\left(0^{-} \mid 0^{+}\right)}$are the partitioning coefficient respectively at the pore entrance and outlet defined by the modified Donnan equations:

$$
\begin{gathered}
\frac{\overline{c_{l}}\left(0^{+}\right)}{c_{i}\left(0^{-}\right)}=\Lambda_{i,\left(0^{-} \mid 0^{+}\right)}=\phi_{i} \frac{\gamma_{i}\left(0^{-}\right)}{\gamma_{i}\left(0^{+}\right)} e^{-z_{i} \Delta \psi_{D,\left(0^{+} \mid 0^{-}\right)}} e^{-\Delta W_{i, B o r n}^{\prime}} e^{-\Delta W_{i, I m\left(0^{-} \mid 0^{+}\right)}^{\prime}} \\
\frac{\overline{c_{l}}\left(\Delta z^{-}\right)}{c_{i}\left(\Delta z^{+}\right)}=\Lambda_{i,\left(\Delta z^{-} \mid \Delta z^{+}\right)}=\phi_{i} \frac{\gamma_{i}\left(\Delta z^{+}\right)}{\gamma_{i}\left(\Delta z^{-}\right)} e^{-z_{i} \Delta \psi_{D,\left(\Delta z^{-} \mid \Delta z^{+}\right)}} e^{-\Delta W_{i, B o r n}^{\prime}} e^{-\Delta W_{i, I m\left(\Delta z^{-} \mid \Delta z^{+}\right)}^{\prime}}
\end{gathered}
$$


where $\Delta \psi_{D,\left(0^{+} \mid 0^{-}\right)}$and $\Delta \psi_{D,\left(\Delta z^{-} \mid \Delta z^{+}\right)}$account for the normalized Donnan potential respectively at the entrance and the outlet of the pore and $\phi_{i}$ denotes the steric partitioning, bounded between 0 and 1 . The $\gamma_{i}$ are the activity coefficients calculated according to the extended Debye-Hückel equation:

$$
\log \left(\gamma_{i}\right)=-\frac{A z_{i}^{2} \sqrt{I}}{1+\left(B r_{i} \sqrt{I}\right)}
$$

with

$$
\begin{gathered}
A=\frac{q^{2} F}{\ln (10) \times 4 \pi \sqrt{2}\left(\varepsilon_{0} \varepsilon_{r} R T\right)^{3 / 2}} \\
B=F \sqrt{-\frac{2}{\varepsilon_{0} \varepsilon_{r} R T}}
\end{gathered}
$$

Where $\mathrm{R}$ is the ideal gas constant, $\mathrm{q}$ the elementary charge, $\varepsilon_{r}$ the dielectric constant of the medium under consideration and I its ionic strength.

As this work focuses on NF of highly concentrated electrolyte solutions, the image charge effect has been neglected in the partitioning equations, which is justified by the screening of this dielectric effect at high concentration $[22,26]$.

Over a first phase, the separation properties of the membrane are assessed through the intrinsic rejection rate:

$$
R_{i}=1-\frac{c_{i}\left(\Delta z^{+}\right)}{c_{i}\left(0^{-}\right)}
$$


As the concentration polarisation is neglected, for all the part concerning the model development it is also equal to the apparent rejection:

$$
R_{\text {app }}=1-\frac{C_{f}}{C_{i}\left(0^{-}\right)}
$$

Where $C_{f}$ is the feed concentration.

\section{Model simplification}

\subsection{Preliminary studies on SEDE model}

As mentioned in introduction, most of the traditional nanofiltration model consider an homogeneous charge density along the pore. Even though this assumption remains questionable in the general case, it proved to be a reliable assumption in numerous situations including, for example, the studies of ceramic membrane [39,58-60] or TFC membranes[2830]. Moreover, the obvious difficulty to determine the fashion of the charge distribution inside pores measuring no more than a few nanometre, makes it the most convenient hypothesis to adopt. Homogeneous charge density models are therefore interesting for a relatively large category of membranes many commercially available models [61].

In order to simplify this model the evolution of the electric field along the pore has been compared for different electrolytes. Considering a uniform fixed charge of -10 mmol. $\mathrm{L}^{-1}$, a dielectric constant of 40 for the confined solution, a pore radius of $0.43 \mathrm{~nm}$ and a thickness to porosity ratio of $5 \mu \mathrm{m}$, the results obtained for simple salt solutions are shown in Fig. 2 and those for electrolyte mixture in Fig. 3. (the results for larger pores and lower fixed charge densities are presented in the Supporting Information, section 1) 
(i)

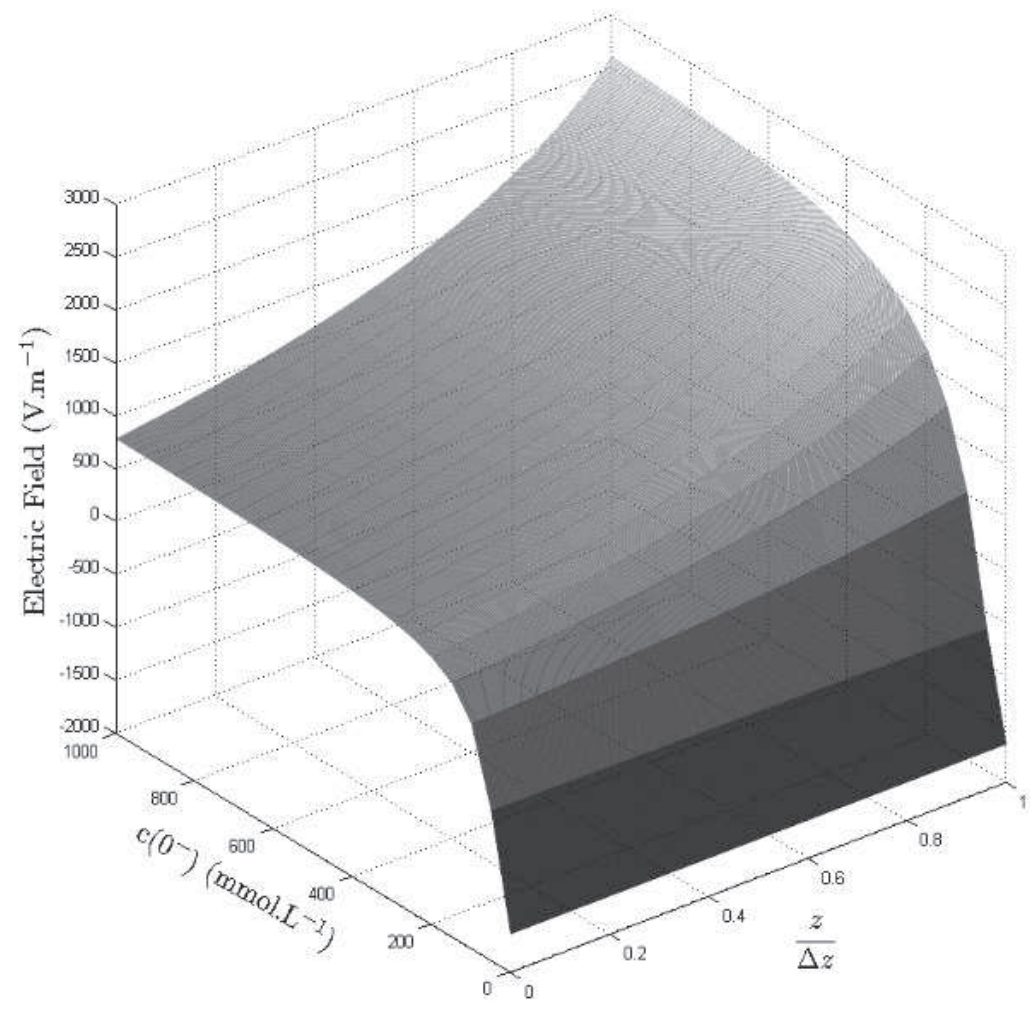

)

(ii)

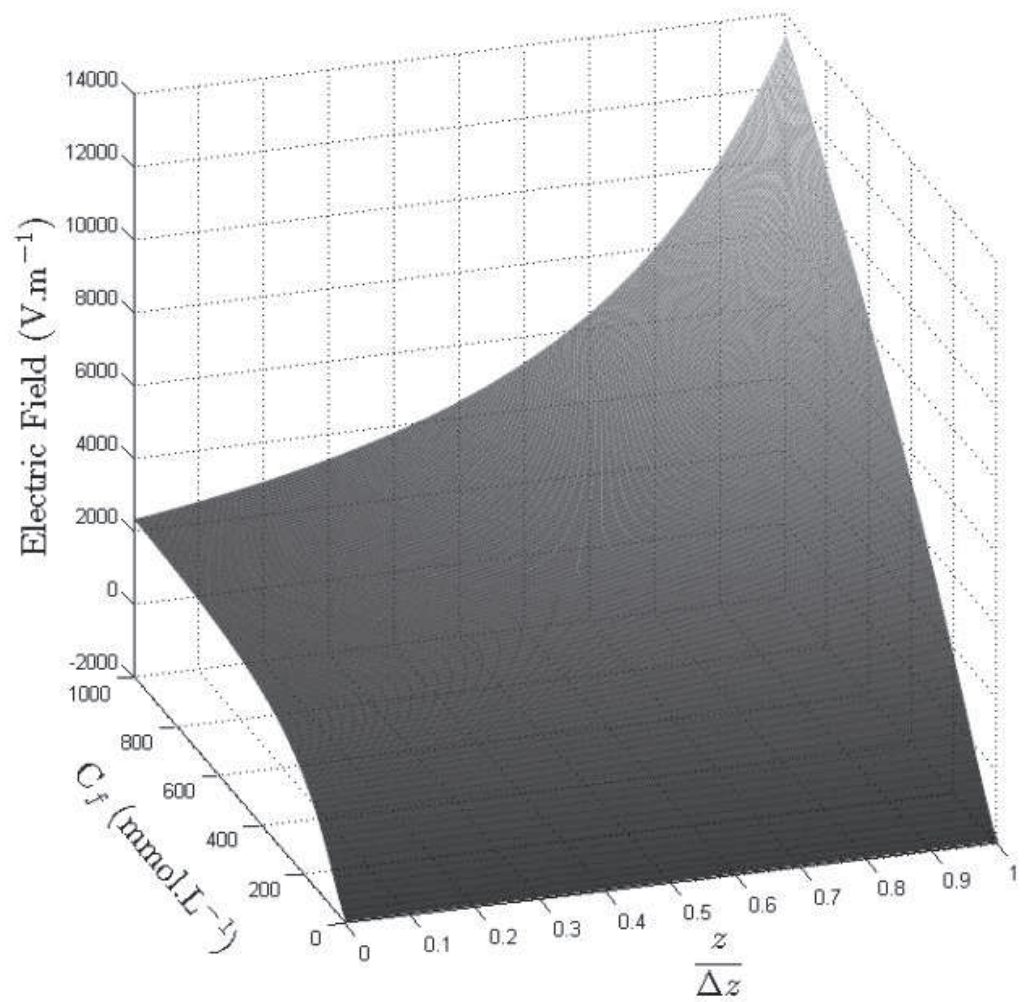


(iii)

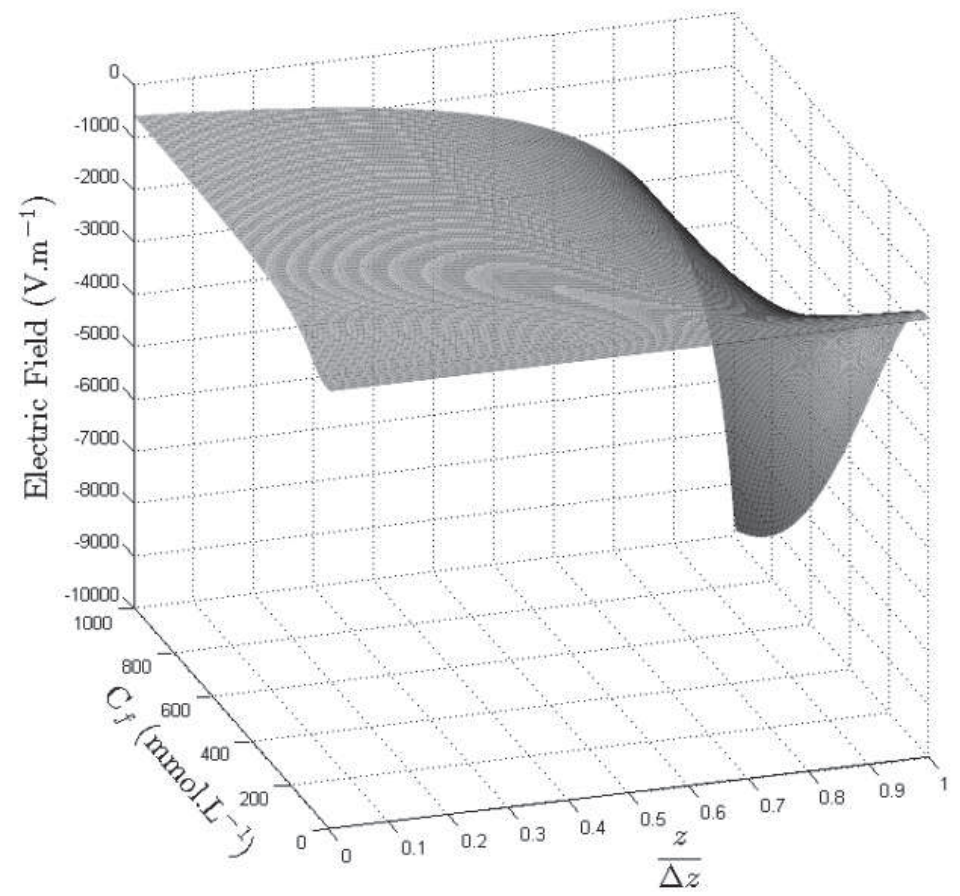

Figure 2. Representation of the electric field along the pore as a function of the concentration for different simple salt solutions. Figures (i), (ii) and (iii) respectively represents the electric field for $\mathrm{NaCl}, \mathrm{CaCl}_{2}$ and $\mathrm{Na}_{2} \mathrm{SO}_{4}$. The parameters chosen for the membrane are a pore radius of $0.43 \mathrm{~nm}$, a thickness over porosity ratio of $5 \mu \mathrm{m}$ and a dielectric constant inside the pore of 40. The volumetric flux is $J_{v}=3.9 \times 10^{-5} \mathrm{~m} \cdot \mathrm{s}^{-1}$.

The electric fields observed for different simple salt solutions exhibit remarkable differences. While all of them seems to present a relatively constant negative electric field at low concentration, their behaviour strongly diverge at high concentration, depending on the nature of the ions in solution. This is convincingly explained by the fact that, at higher concentration the diffusion potential is imposed by the fastest ion inside the pore. Indeed, at low concentration the negative electric field arises as to maintain the electroneutrality inside the pore, taking the sign of the homogeneous charge of the membrane into account. Therefore, in the case of a negatively charge pore cations are attracted inside the membrane, which causes a negative electric field to arise in order to drive the anions on the permeate side. However at 
high concentration, the pore charge is quickly neutralized by the positive charges and a new regime is established in which the fastest ion is accumulated at the outlet of the pore. Therefore an electric field opposed to the sign of the fastest ion naturally arises in order to reverse this tendency. Following this reasoning the figure above are corroborated by the sequence of ions mobility $\mathrm{Cl}^{-}>\mathrm{Na}^{+}>\mathrm{SO}_{4}{ }^{2-}>\mathrm{Ca}^{2+}$.

(i)

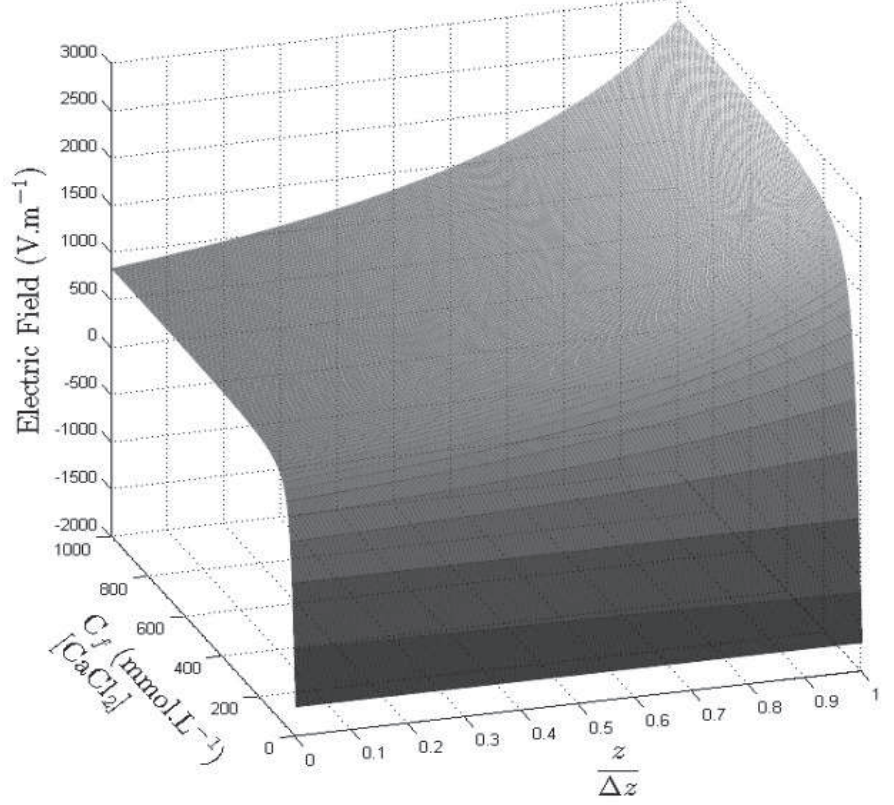

(ii)

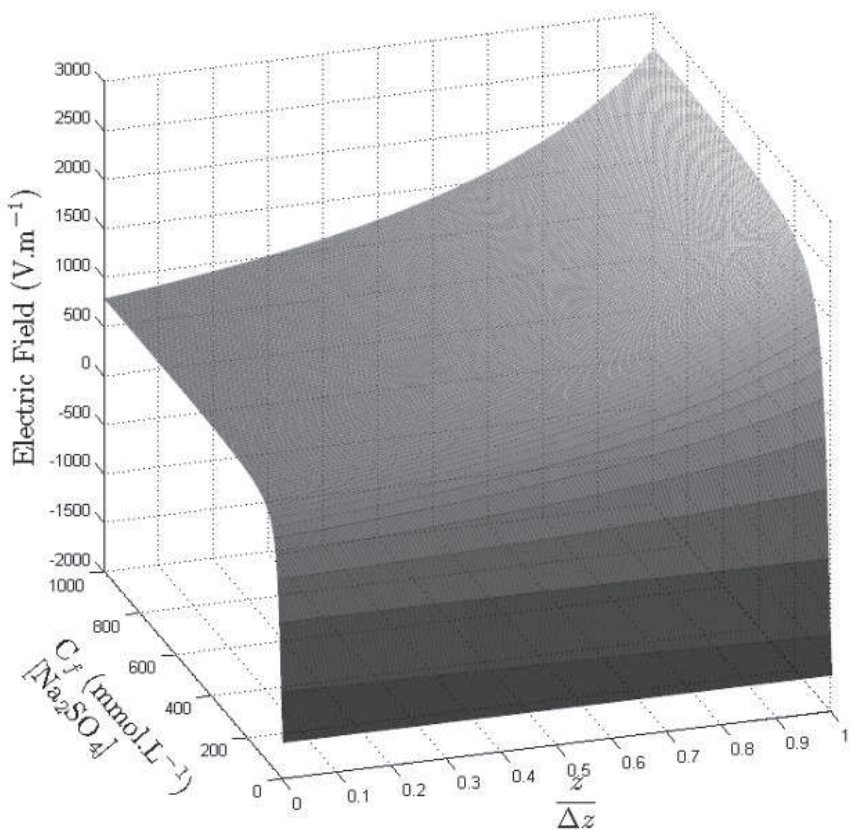


Figure 3. Representation of the electric field along the pore as a function of the concentration for different simple salt solutions. Figure (i) and (ii) respectively represents the electric field for an electrolyte mixture composed of $\mathrm{NaCl}$ and $\mathrm{CaCl}_{2}$ and one of $\mathrm{NaCl}$ and $\mathrm{Na}_{2} \mathrm{SO}_{4}$. The parameters chosen for the membrane are a pore radius of $0.43 \mathrm{~nm}$, a thickness over porosity ratio of $5 \mu \mathrm{m}$ and a dielectric constant inside the pore of 40 . The volume flux is $J_{v}=3.9 \times$ $10^{-5} \mathrm{~m} \cdot \mathrm{s}^{-1}$

The electric fields profiles along the pore for the electrolyte mixture considered are similar to each other. Besides, it is interesting to note the similarity with the electric field plotted in the case of $\mathrm{NaCl}$. We can therefore deduce that the mechanism at stake in the formation of the electric field is similar with those described in the case of simple salt solutions. It is relevant to note that these observations on the evolution of the electric field are corroborated, at least partly, by the results of Vezzani et al. [23],

\subsection{Model simplification}

This preliminary study of the electric field for an homogeneous charge density along the pore exhibit a relatively constant negative electric field at small concentration. Based on those observations a simplification of the SEDE model is thereafter derived.

The idea is to average the electric potential gradient along the pore, in order to simplify the resolution of the concentration gradient (4):

$$
\left\langle\frac{d \bar{\psi}}{d z}\right\rangle_{z}=\frac{1}{\Delta z} \int_{0}^{\Delta z} \frac{d \bar{\psi}(z)}{d z} d z=\frac{1}{\Delta z} \int_{0}^{\Delta z} d \bar{\psi}(z)=\frac{\Delta \bar{\psi}}{\Delta z}
$$


Subsequently, the expression of the electric field in the transportation equation (5) has been replaced by its average value, leading to a simple first order linear differential equation for the concentration gradient inside the pore:

$$
\frac{d \bar{c}_{l}(z)}{d z}=\left(\frac{P e_{i}}{\Delta z}-z_{i} \frac{F}{R T} \frac{\Delta \bar{\psi}}{\Delta z}\right) \bar{c}_{l}(z)-\frac{1}{K_{i, c}} \frac{P e_{i}}{\Delta z} c_{i}\left(\Delta z^{+}\right)
$$

The latter equation, considering the normalised potential difference $\Delta \overline{\psi_{N}}=\frac{F}{R T} \Delta \bar{\psi}$ and given the boundary conditions (11.1) and (11.2) respectively applicable to the pore inlet and outlet, leads to the following solution (see the Appendix for the details):

$$
\frac{c_{i}\left(\Delta z^{+}\right)}{c_{i}\left(0^{-}\right)}=\frac{\Lambda_{i,\left(0^{-} \mid 0^{+}\right)} K_{i, c}\left(P e_{i}-z_{i} \Delta \overline{\psi_{N}}\right) e^{\left(P e_{i}-z_{i} \Delta \overline{\psi_{N}}\right)}}{\Lambda_{i,\left(\Delta z^{-} \mid \Delta z^{+}\right)} K_{i, c}\left(P e_{i}-z_{i} \Delta \overline{\psi_{N}}\right)-P e_{i}\left(1-e^{\left(P e_{i}-z_{i} \Delta \overline{\psi_{N}}\right)}\right)}
$$

And therefore, the rejection rate can be estimated as:

$$
R_{i}=1-\frac{\Lambda_{i,\left(0^{-} \mid 0^{+}\right)} K_{i, c}\left(P e_{i}-z_{i} \Delta \overline{\psi_{N}}\right) e^{\left(P e_{i}-z_{i} \Delta \overline{\psi_{N}}\right)}}{\Lambda_{i,\left(\Delta z^{-} \mid \Delta z^{+}\right)} K_{i, c}\left(P e_{i}-z_{i} \Delta \overline{\psi_{N}}\right)-P e_{i}\left(1-e^{\left(P e_{i}-z_{i} \Delta \overline{\psi_{N}}\right)}\right)}
$$

Where $P e_{i}$ is the Peclet number for the ion $i$, equal to $\left(J_{v} K_{i, c} z_{A}\right) / K_{i, d} D_{i, \infty}$, the quantity $z_{A}$ corresponding to the ratio of the membrane thickness over its porosity.

In the most general case of multi-ionic solutions, this model can be solved using the following process:

1. Determine the parameters of the model and calculate $\Delta W_{i, B o r n}^{\prime}$ according to equation (6). 
2. Calculate $\Delta \psi_{D,\left(0^{+} \mid 0^{-}\right)}, \Delta W_{i, \operatorname{Im}\left(0^{-} \mid 0^{+}\right)}^{\prime}$ and $\frac{\gamma_{i}\left(0^{+}\right)}{\gamma_{i}\left(0^{-}\right)}$. This can be achieved by solving the system formed by equations (8.1), (12) and (21). The latter is deduced as a combination of the electroneutrality equation (2) inside the pore and the boundary condition (11.1):

$$
\sum_{i} z_{i} \Lambda_{i,\left(0^{-} \mid 0^{+}\right)} c_{i}\left(0^{-}\right)+X=0
$$

3. Calculate $\Delta \psi_{D,\left(\Delta z^{-} \mid \Delta z^{+}\right)}, \Delta W_{i, \operatorname{Im}\left(\Delta z^{-} \mid \Delta z^{+}\right)}^{\prime}, \frac{\gamma_{i}\left(0^{+}\right)}{\gamma_{i}\left(0^{-}\right)}$and $\Delta \overline{\psi_{N}}$. This can be achieved by solving the system formed by (8.2), (12), (22). The latter is deduced by injecting the expression of $c_{i}\left(\Delta z^{+}\right)$given by (19) in the electroneutrality conditions on the permeate side (22.1) and at the pore outlet (22.2):

$$
\left\{\begin{array}{c}
\sum_{i} z_{i} \frac{\Lambda_{i,\left(0^{-} \mid 0^{+}\right)} K_{i, c}\left(P e_{i}-z_{i} \Delta \overline{\psi_{N}}\right) e^{\left(P e_{i}-z_{i} \Delta \overline{\psi_{N}}\right)} c_{i}\left(0^{-}\right)}{\Lambda_{i,\left(\Delta z^{-} \mid \Delta z^{+}\right)} K_{i, c}\left(P e_{i}-z_{i} \Delta \overline{\psi_{N}}\right)-P e_{i}\left(1-e^{\left(P e_{i}-z_{i} \Delta \overline{\psi_{N}}\right)}\right)}=0 \\
\sum_{i} z_{i} \frac{\Lambda_{i,\left(0^{-} \mid 0^{+}\right)} \Lambda_{i,\left(\Delta z^{-} \mid \Delta z^{+}\right)} K_{i, c}\left(P e_{i}-z_{i} \Delta \overline{\psi_{N}}\right) e^{\left(P e_{i}-z_{i} \Delta \overline{\psi_{N}}\right)} c_{i}\left(0^{-}\right)}{\Lambda_{i,\left(\Delta z^{-} \mid \Delta z^{+}\right)} K_{i, c}\left(P e_{i}-z_{i} \Delta \overline{\psi_{N}}\right)-P e_{i}\left(1-e^{\left(P e_{i}-z_{i} \Delta \overline{\psi_{N}}\right)}\right)}+X=0
\end{array}\right.
$$

4. Calculate $R_{i}$ using equation (20).

This simplified model using the averaged potential approximation is abbreviated as SEDEAPG. Its algorithm, presented in Fig. 4, is to be compared with that of the original model: as the nonlinear differential equation for the concentration gradient is dropped, the resourceconsuming iterative process on the RK4 algorithm is not needed anymore and a lot of computational resource is saved. 


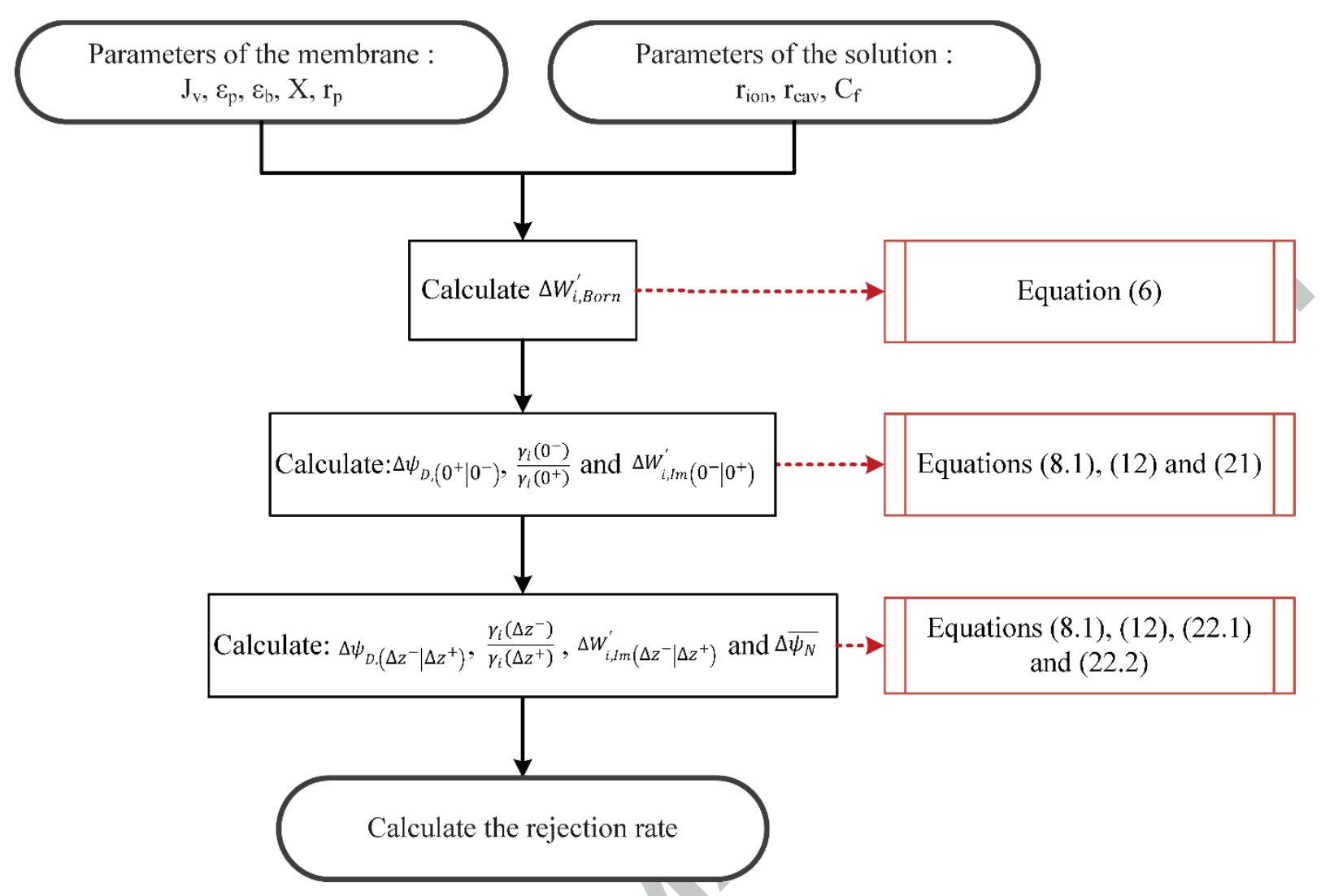

Figure 4. Algorithm of the SEDE-APG model

\subsection{Model assessment}

Using the SEDE-APG the rejections predicted for different moderately concentrated $(0.1 \mathrm{M}$ to $0.2 \mathrm{M}$ ) salt solutions were compared with the original SEDE model. Moreover, in order to stress the accuracy of the model at different charge densities, the rejection rate has been simulated for charges of $-10 \mathrm{mmol} \cdot \mathrm{L}^{-1}$ and $-30 \mathrm{mmol} . \mathrm{L}^{-1}$. The other parameters of the membrane chosen for simulations are a pore radius of $0.43 \mathrm{~nm}$ and a thickness over porosity ratio of $5 \mu \mathrm{m}$. The former corresponding to the characteristic of a NF-270 membrane [29], a typical commercial membrane, while the latter is an average value determined by Bowen and Mohammed from twenty-nine commercial NF membranes [62]. The dielectric constant of 40 for the inside of the nanopore, roughly correspond to that obtained by Oatley et al. [29]. The results are presented in Fig. 5 and Fig. 6. At this stage it is also important to stress that for 
higher concentrations, the simplified model remain coherent with the original one in spite of the electric field variations arising along the pore (see Supporting Information). Later on

2.3.1. Single electrolytes solutions

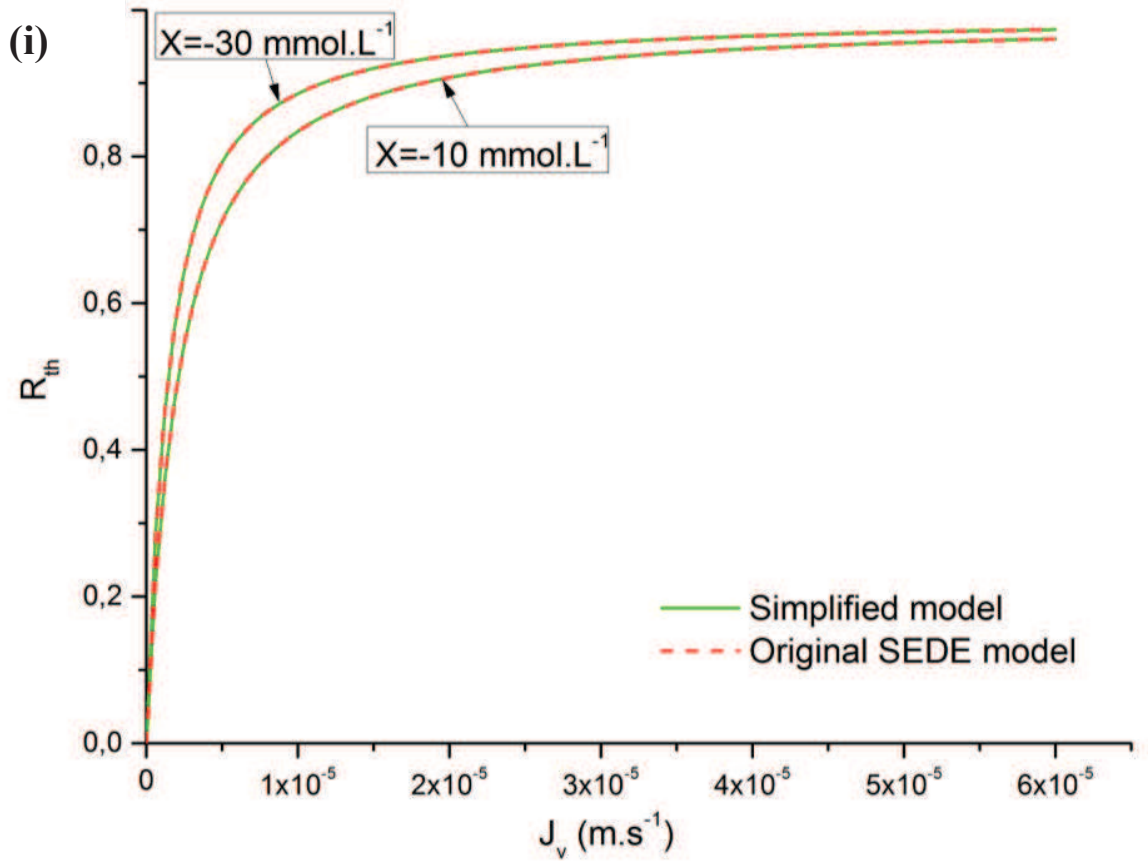

(ii)

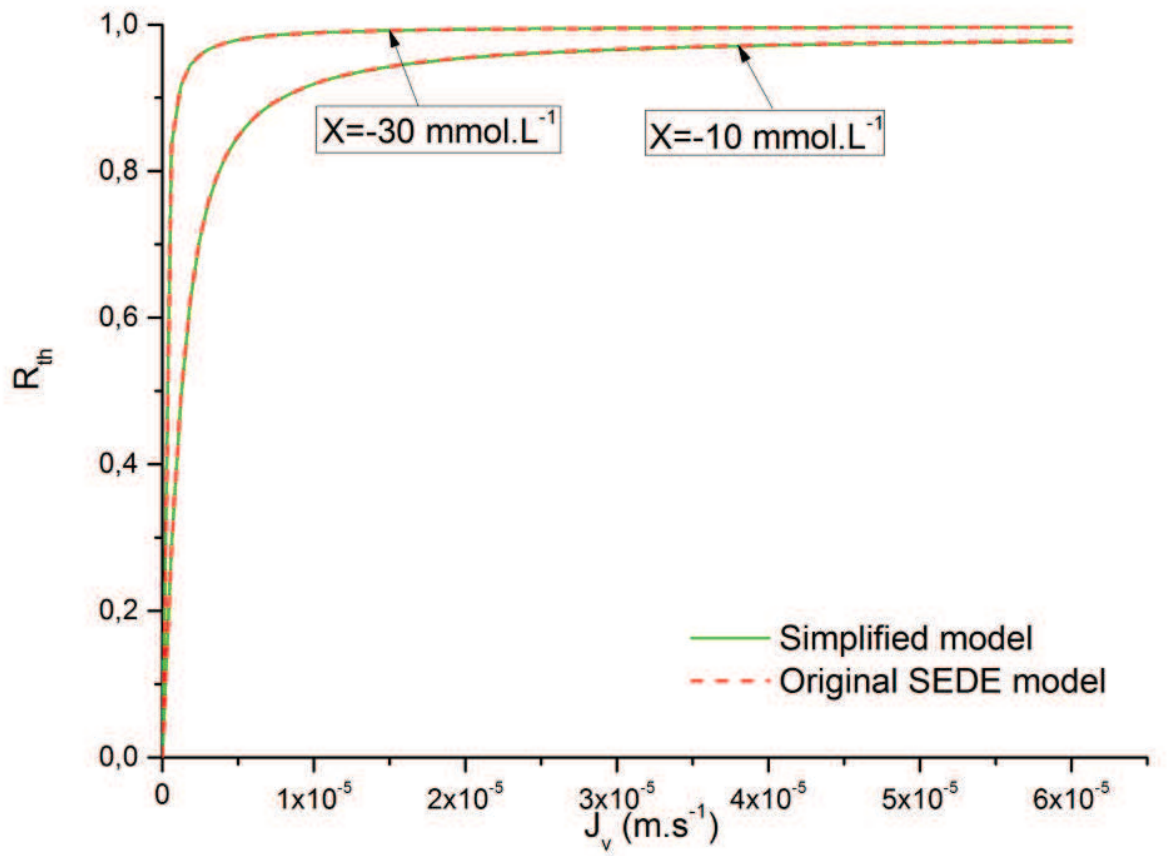




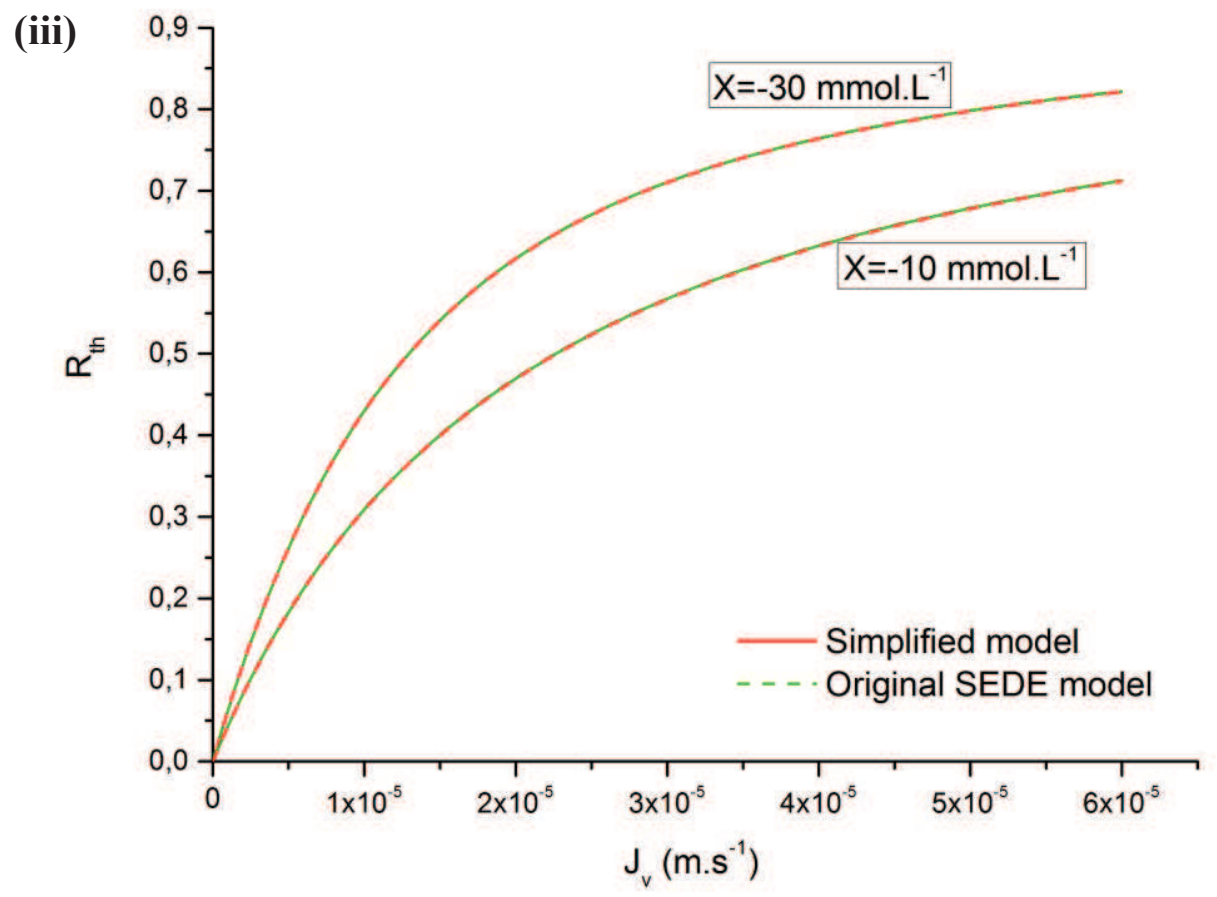

Figure 5. Comparison of the rejection rate against the volume flux using SEDE-APG and the original SEDE model. Figures (i), (ii) and (iii) respectively correspond to the rejections of $\mathrm{CaCl}_{2}, \mathrm{Na}_{2} \mathrm{SO}_{4}$ and $\mathrm{NaCl}$. Each of the solution is concentrated at 100 mmol.L-1. The membrane parameters are as described in the paragraph above.

Fig. 5 shows an excellent agreement between the two models. Therefore this new model establishes itself as a performant alternative to the current mechanistic models in the case of homogeneous charged pores.

Moreover, the simplicity of the SEDE-APG allows a better understanding and analysis of the mechanisms at stake in the rejection process. Indeed the direct expression of the rejection rate given by equation (20) makes this model an interesting tool to quantify the share of each phenomenon in the rejection process. This expression is however not accessible in the original SEDE model.

\subsubsection{Electrolytes mixtures}



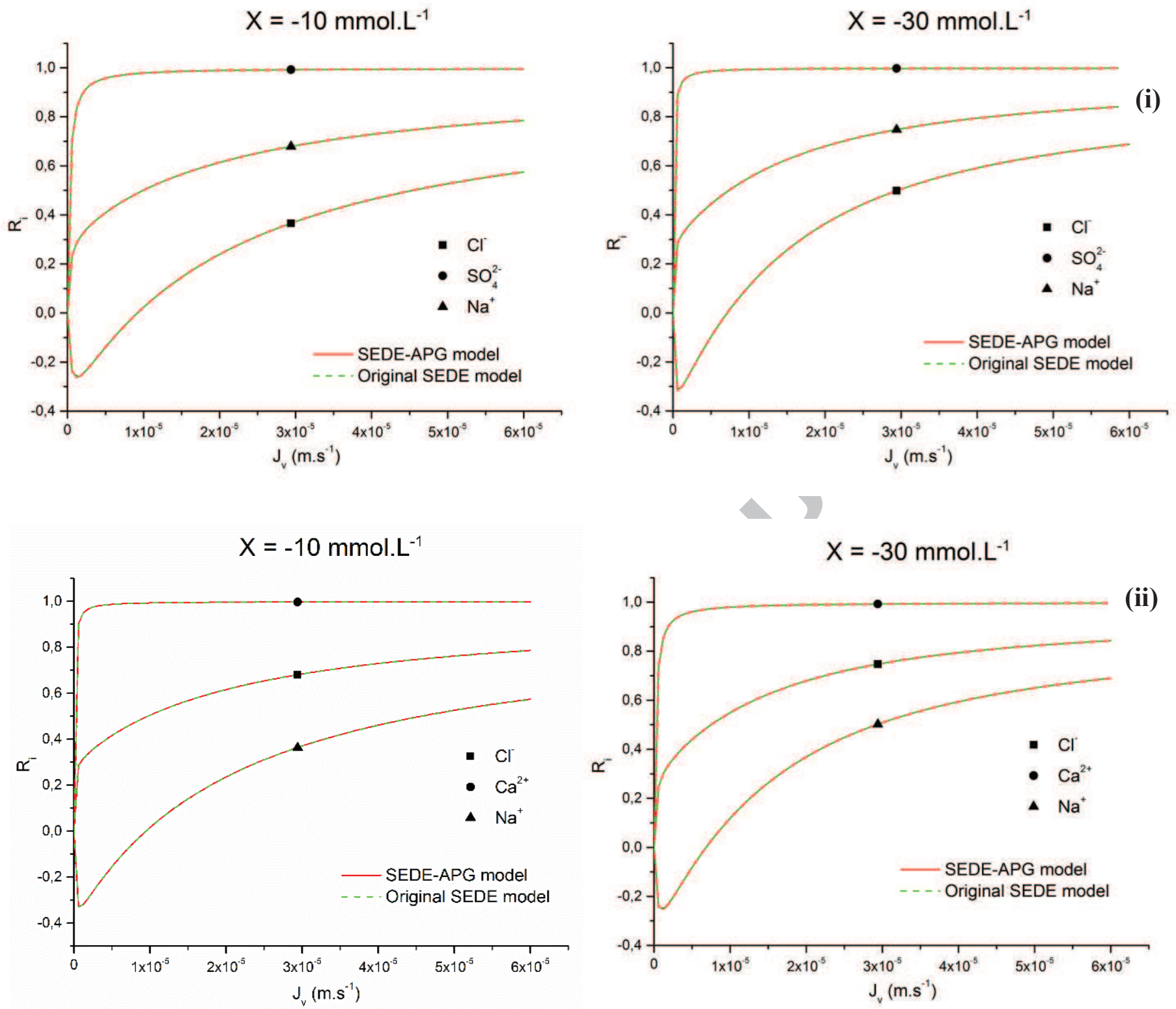

Figure 6. Comparison of the rejection rate against the volume flux using SEDE-APG and the original SEDE model. Figure (i) correspond to an electrolyte solution of 100 mol.L $\mathrm{L}^{-1} \mathrm{Na}_{2} \mathrm{SO}_{4}$ and 200 mol.L-1 NaCl. Figure (ii) correspond to an electrolyte solution of 100 mol.L ${ }^{-1} \mathrm{CaCl} 2$ and $200 \mathrm{~mol}^{-1} \mathrm{~L}^{-1} \mathrm{NaCl}$. In each figure, the results are represented for charge densities of -10 mmol. $\mathrm{L}^{-1}$ and $-30 \mathrm{mmol} . \mathrm{L}^{-1}$.

Fig. 6 confirm the good results obtained for single salt solution in the case of electrolyte mixtures. Here again the results show a quasi-perfect with the original model. It is worth 
mentioning that the new model successfully predicts the phenomenon of negative rejection commonly observed in nanofiltration.

\subsubsection{Computational performance}

Besides from its simplicity and easier implementation, the computation speed is greatly reduced. Fig. 7 shows a diminution in computation time greater than 1 order of magnitude. Moreover, in the case of the simplified model, the computation time is less dependent of the complexity of the system considered.

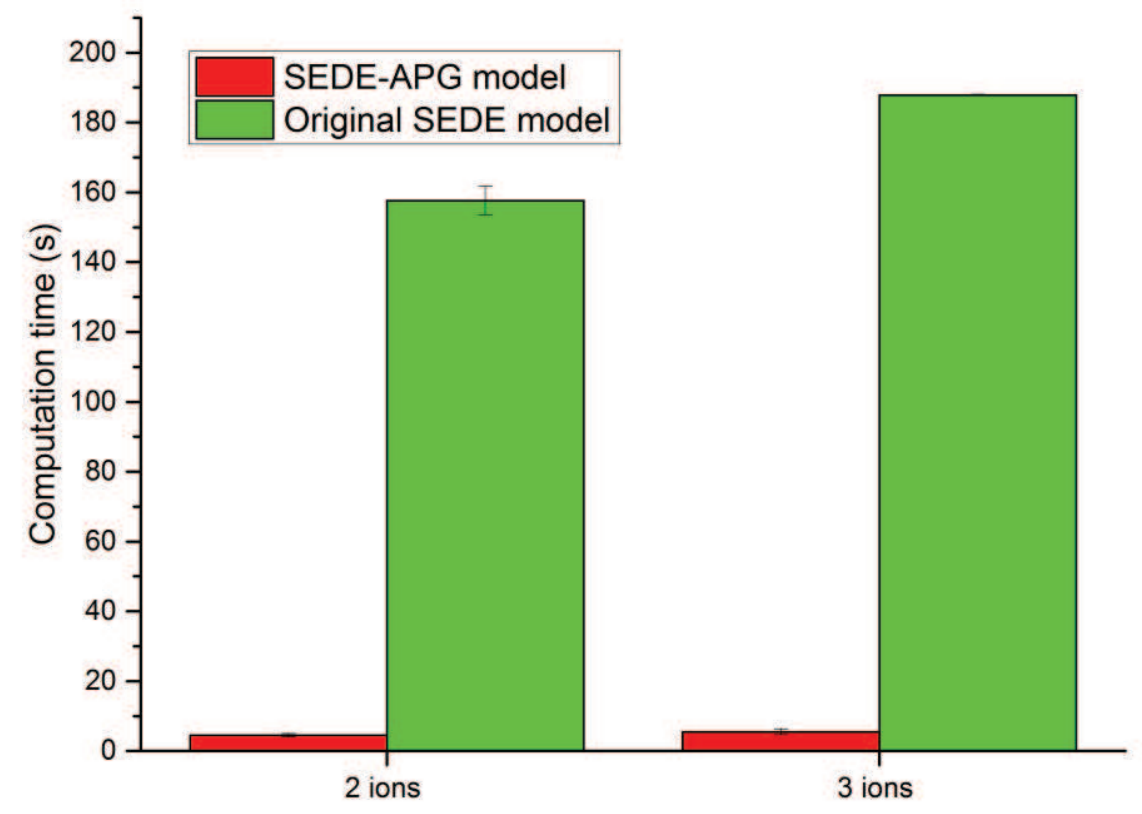

Figure 7. Computation speed of the different models, considering 2 ions and 3 ions mixtures.

\section{Application}

\subsection{Data and methods}


In order to prove the predictive potential of this simplified model, the work of Pérez-Gonzalez et al. [63] on the nanofiltration separation of $\mathrm{SO}_{4}{ }^{2-}$ and $\mathrm{Cl}^{-}$anions in desalination brines has been investigated using the SEDE-APG approach. For this purpose, the predictions of the simplified model were confronted to the experimental results proposed in the aforementioned study which considered model brines with a constant concentration of sodium sulphate of approximately $1 \mathrm{M}$ and a varying concentration of sodium chloride between $0.14 \mathrm{M}$ and $1.13 \mathrm{M}$ [63]. To compare the predictions with the experimental results, a least square objective function $S_{y}$ has been used. It is defined as follow for $\mathrm{n}$ solutes corresponding to $\mathrm{j}$ data points:

$$
S_{y}=\sqrt{\frac{\sum_{1}^{n} \sum_{1}^{j}\left(R_{o b s}-R_{a p p}\right)^{2}}{j n-1}}
$$

Where $R_{a p p}$ is the calculated apparent rejection from equation (16).

The characteristics of the membrane were taken from the literature. Several sources agree on an average pore size of $0.43 \mathrm{~nm}[29,64,65]$ and a pure water permeability of $L_{p}=3.75 \times$ $10^{-11}[64]$ for the NF270 membrane considered in this study, while the thickness to porosity ratio $z_{A}$ has been determined by adopting the classical Hagen-Poiseuille flow approach [66]:

$$
z_{A}=\frac{r_{p}^{2}}{8 \eta L_{p}}=0.69 \mu \mathrm{m}
$$

Where $\eta$ is the dynamic viscosity of water at $\mathrm{T}$.

It should be noted that the thickness to porosity ratio thus obtained is a dependent parameter, and is ten-fold smaller than the one obtained using SEM data in the original work of PerezGonzales et al. [63]. The approach chose in this paper aims at increasing the internal coherence of the model. Indeed, the original DSPM model, is known to suffer from 
inconsistencies in the values of $z_{A}$ which are found to change with the nature of the electrolyte solution.

The volumetric flux is related to the effective gradient by the following equation:

$$
J_{v}=L_{p}(\Delta P-\Delta \pi)
$$

Where $\Delta P$ is the applied pressure gradient and $\Delta \pi$ the osmotic pressure gradient. The osmotic pressure gradient is determined by the difference between the osmotic pressures in the retentate and the permeate estimated through the Van't Hoff law.

For this application the concentration polarisation has been taken into account, as the concentrations considered being relatively high. For this purpose, the mass transfer coefficient for each ion was assessed using the same correlation with the one proposed by the original paper:

$$
k_{m}=\frac{D_{\infty}}{d_{h}} 0.3125 \operatorname{Re}^{0.57} \mathrm{Sc}^{1 / 3}
$$

Where $d_{h}$ is the hydraulic diameter of the SEPA-CF membrane cell [67], Re the Reynolds number and Sc the Schmidt number.

The concentration polarisation has been calculated using the classical Spiegler-Kedem approach:

$$
\frac{c_{i}\left(0^{-}\right)-c_{i}\left(\Delta z^{+}\right)}{C f-c_{i}\left(\Delta z^{+}\right)}=e^{J_{v} / k_{m}}
$$


The values of charge densities used here correspond to those calculated by Pérez-Gonzalez et al. from the streaming potential measurements [63]. They are reminded in the table below:

\begin{tabular}{lll}
$\boldsymbol{\alpha}=\frac{\left[\mathrm{Cl}^{-}\right]}{\left[\mathrm{SO}_{4}^{2-}\right]}$ & $\boldsymbol{N a C l}(\mathbf{M})$ & $\boldsymbol{X}\left(\mathbf{m o l . m}^{-3}\right)$ \\
\hline 1.7 & & \\
5.1 & 0.14 & -265 \\
10.2 & 0.42 & -459 \\
13.6 & 0.85 & -649 \\
& 1.13 & -750
\end{tabular}

Table 1. Charge densities deduced from streaming potential measurements for each model brines. Values taken from [63].

\subsection{Results and discussion}

Using the theoretical framework described above, the SEDE-APG model has been confronted to experimental results [63] by using three different approaches:

(a) A full model approach (Donnan, steric, Born and image effects)

(b) A Donnan, steric and Born effects approach (neglecting image effects)

(c) A Donnan and steric effects only approach (neglecting both dielectric effects). This approach is similar to that of the original research paper. Here it aims at confirming the influence of the thickness to porosity ratio dependency on water permeability.

The results are presented in Fig. 8 below: 

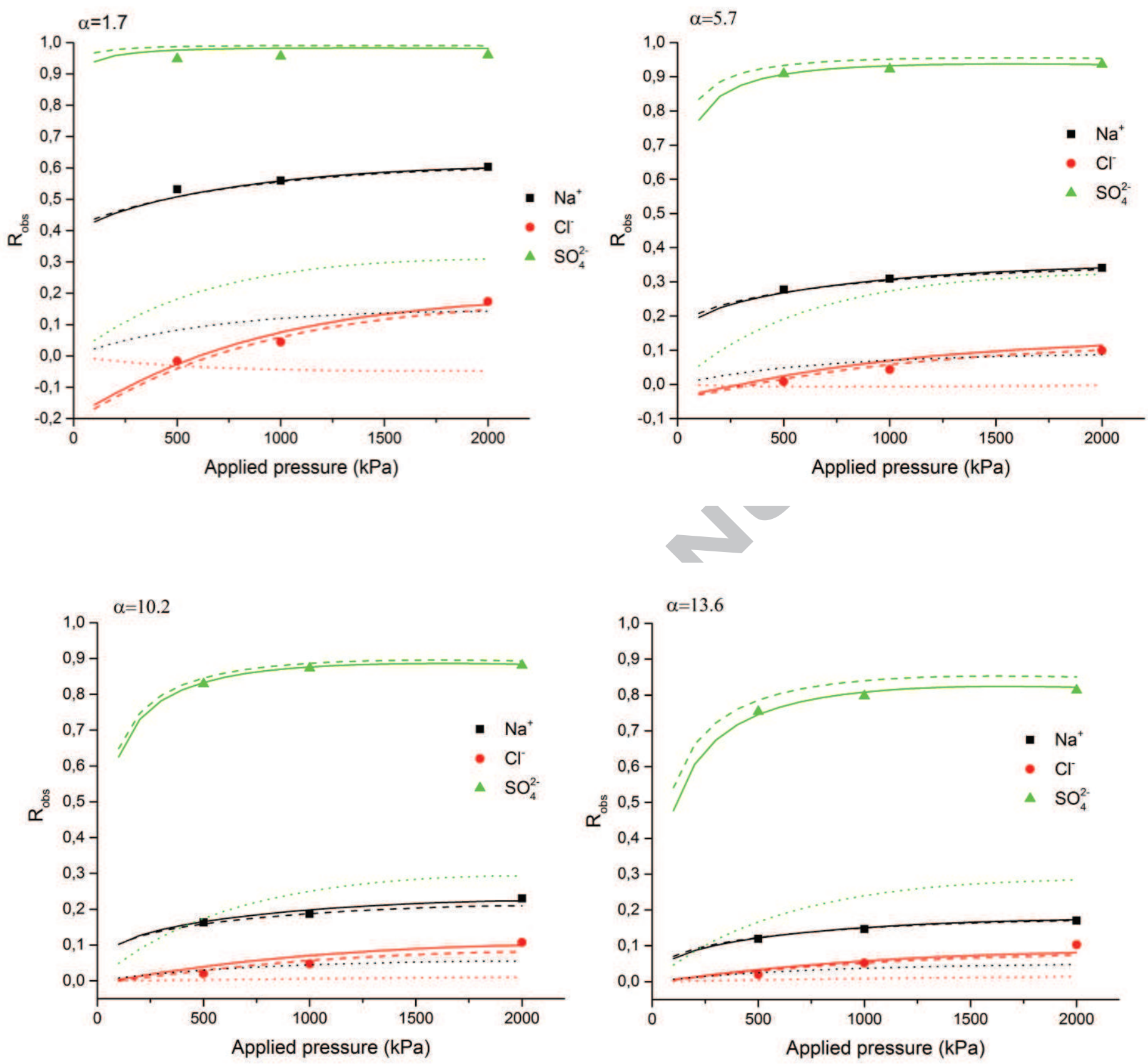

Figure 8. Experimental (symbols) and predicted ions rejections. The predicted ions rejections corresponding either to the approach (a) (dash lines - - - .), (b) (solid lines ) or (c) (dot lines ......) described earlier.

The results and parameter used for the different approaches are consigned in Table 2. 
(a)

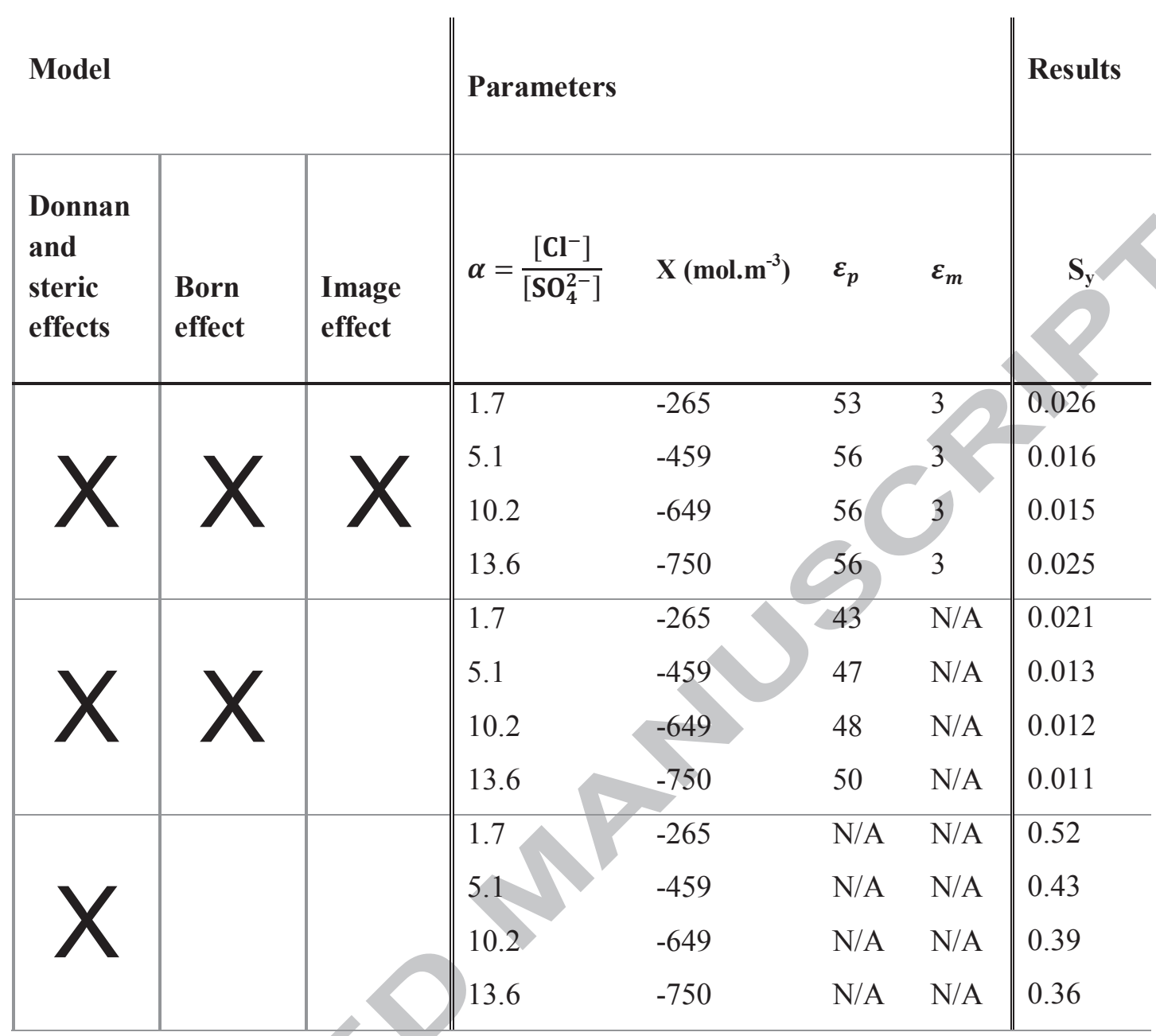

Table 2. Parameters used and results obtained for each approach (a), (b) and (c) described above.

It is worth mentioning that the dielectric constant of the polyamide matrix can hardly be considered as a fitting parameter as it is fixed to $\varepsilon_{m}=3$ corresponding to an established experimental data widely available in the literature [38]. However the shift in the dielectric constant of the confined medium is still relatively poorly understood. Recent computer experiments confirmed the phenomenon [32-35], but the no reliable method exists to quantitatively assess it or model it in the general case. Interestingly enough a recent computational study on a charged silica nanotube by Renou et al. [34] confirms that, at negative surface charges, the dielectric constant of a confined water solution could be smaller than that of the bulk solution. 
From Fig. 8 it is clear enough that the Donnan/steric approach is not enough to predict the ions rejection when $z_{A}$ is related to the water permeability. However fitting procedures of this parameter have proven to yield inconsistencies in its value [17-19], hence the need to take dielectric phenomena into account. The Table 2 confirms the good results from Fig. 8 for the model (a) and (b) which respectively deviate by no more than $2.6 \%$ and $2.1 \%$ from the experimental results. An interesting feature of the full model (a) is that the fitted dielectric constant of the confined medium remains relatively constant, while for the model (b) it is increasing along with the concentration. As far as NF modeling goes, a shift in concentration is often assumed to have no effect on the dielectric constant inside the pore, nevertheless it is probable that the presence of ions influence the orientation of water molecules inside the nanopore. To our knowledge this work is the first to clearly compare these two approaches together against the same experimental data. While they both seem relatively accurate, additional data on the confined solution would be necessary to conclude on one or the other approach.

\section{Conclusion}

By stressing that the electric field along the pore can confidently be averaged in the case of homogeneous charge distribution, the SEDE-APG model was developed and assessed. This simple model, based on a first order differential equation for the concentration gradient inside the pore, is thus compared to the original SEDE model in terms of accuracy and computational speed.

It exhibits an excellent agreement with the existing theory while reducing the computing speed by more than one order of magnitude. Moreover the resource needed by this new model hardly depends on the complexity of the system. It is likely to be useful for those looking for a fast and accurate tool when trying to predict the performance of a membrane. It is moreover 
easy to implement while giving a good grasp on the role of each phenomenon at stake in the nanofiltration process, as it provides an insightful expression for the rejection rate.

Ultimately this model is confronted with experimental data taken from the literature [63]. Using three different approaches we show how this model is able to predict accurately the separation of polyvalent and monovalent anions using a coherent framework that notably dispenses with the useless fitting on the thickness to porosity ratio present in the original DSPM model. The influence of Born and image effect are also discussed. While taking image forces into account results into a more stable fitting for the dielectric constant inside the pore, the lack of scientific knowledge and data on the matter doesn't allow us to draw a definitive conclusion on which approach is more representative of the reality.

\section{Acknowledgements}

This work is supported by program for Yang Fan Program financed by Science and Technology Commission of Shanghai Municipality (14YF1403200), the Scientific Research Foundation for the Returned Overseas Chinese Scholars (State Education Ministry, 2014) and Young Excellent Talents in Tongji University (2013KJ019).

We wish to express our appreciation for the valuable help from peers around us and all the authors whose articles we referenced. We also would like to thank the anonymous reviewers for supplying their valuable comments.

\section{Notations}

$$
\begin{aligned}
A_{k} & =\text { membrane porosity } \\
c_{i}\left(0^{-}\right) & =\text {charge of the ion } i \text { on the permeate side }\left(\mathrm{mmol} . \mathrm{L}^{-1}\right) \\
\overline{c_{l}}(z) & =\text { concentration profile along the pore }\left(\mathrm{mmol} \cdot \mathrm{L}^{-1}\right) \\
c_{i}\left(\Delta z^{+}\right) & =\text {charge of the ion } i \text { on the retentate side }\left(\mathrm{mmol} . \mathrm{L}^{-1}\right)
\end{aligned}
$$




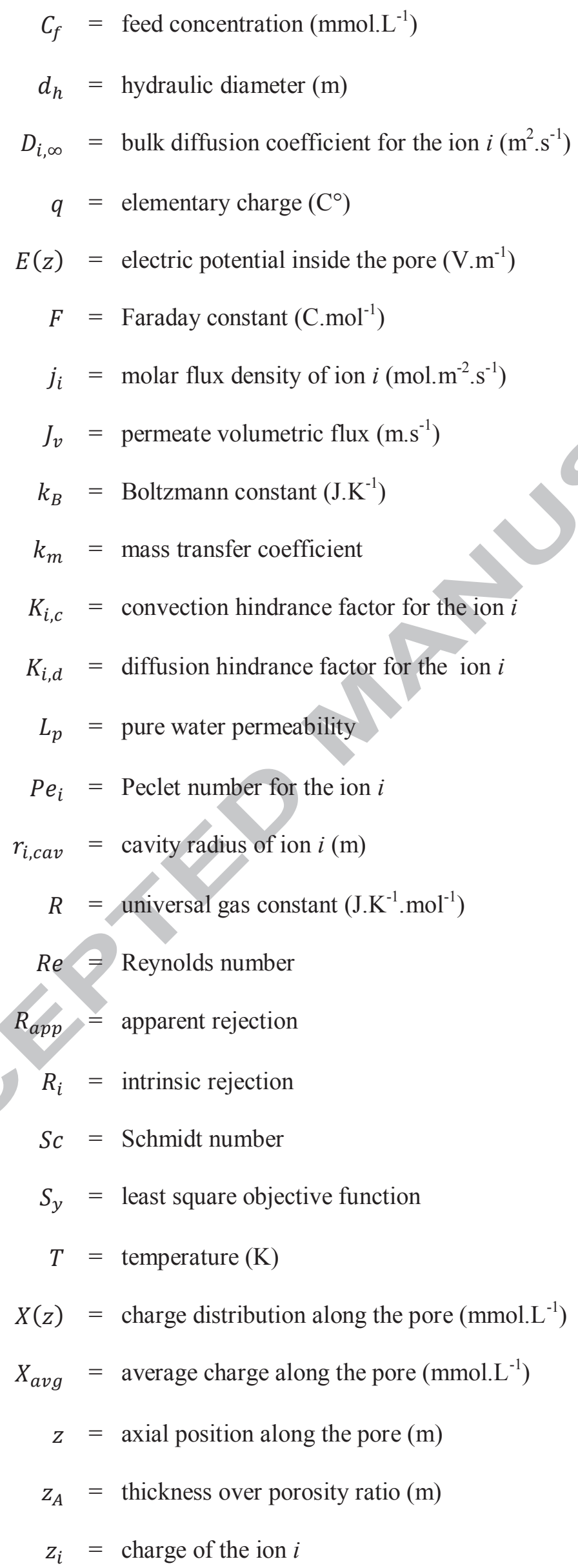




\section{Greek letters}

$\alpha=$ ratio between chloride concentration and sulfate concentration

$\alpha_{i}=$ ratio between the Bjerrum length and the pore size

$\gamma_{i}=$ activity coefficient for the ion $i$

$\eta=$ dynamic viscosity of water

$\Lambda_{i,\left(0^{-} \mid 0^{+}\right)}=$Partition coefficient at the pore inlet for the ion $i$

$\Lambda_{i,\left(\Delta z^{-} \mid \Delta z^{+}\right)}=$Partition coefficient at the pore outlet for the ion $i$

$\Delta P=$ applied pressure gradient $(\mathrm{Pa})$

$\Delta W_{i, B o r n}^{\prime}=$ Born solvation energy barrier for the ion $i\left(\right.$ scaled on $\left.k_{B} T\right)$

$\Delta W_{i, I m\left(0^{-} \mid 0^{+}\right)}^{\prime}=$ Solvation energy barrier due to image forces for the ion $i$ at the pore inlet (scaled on $k_{B} T$ )

$\Delta W_{i, I m\left(\Delta z^{-} \mid \Delta z^{+}\right)}^{\prime}=$ Solvation energy barrier due to image forces for the ion $i$ at the pore outlet (scaled on $k_{B} T$ )

$$
\Delta z=\text { pore length }(\mathrm{m})
$$

$\Delta \pi=$ osmotic pressure difference $(\mathrm{Pa})$

$\Delta \bar{\psi}=$ potential variation inside the pore $(\mathrm{V})$

$\Delta \psi_{D,\left(\Delta z^{-} \mid \Delta z^{+}\right)}=$normalised Donnan potential at the pore outlet

$\Delta \psi_{D,\left(0^{+} \mid 0^{-}\right)}=$normalised Donnan potential at the pore outlet

$$
\begin{aligned}
\Delta \overline{\psi_{N}} & =\text { normalised average potential variation inside the pore } \\
\varepsilon_{0} & =\text { vacuum permittivity }\left(\mathrm{J}^{-1} \cdot \mathrm{C}^{2} \cdot \mathrm{m}^{-1}\right) \\
\varepsilon_{b} & =\text { dielectric constant of the bulk } \\
\varepsilon_{m} & =\text { dielectric constant of the membrane matrix } \\
\varepsilon_{p} & =\text { dielectric constant inside the pore } \\
\mu & =\text { effective reciprocal dimensionless screening length } \\
\phi_{i} & =\text { steric partition coefficient } \\
\bar{\psi}(z) & =\text { electric potential along the pore }(\mathrm{V})
\end{aligned}
$$




\section{Appendix A: Derivation of the transmission equation}

Let us remind the differential equation describing the evolution of concentration inside the pore:

$$
\frac{d \overline{c_{l}}(z)}{d z}=\left(\frac{P e_{i}}{\Delta z}-z_{i} \frac{\Delta \overline{\psi_{N}}}{\Delta z}\right) \bar{c}_{l}(z)-\frac{1}{K_{i, c}} \frac{P e_{i}}{\Delta z} c_{i}\left(\Delta z^{+}\right)
$$

At $\mathrm{z}=0$ inside the membrane, $\overline{c_{l}}(z)=\overline{c_{l}}\left(0^{+}\right)$. Solving the equation (A.1) considering this boundary condition gives:

$$
\overline{c_{l}}(z)=\bar{c}_{l}\left(0^{+}\right) e^{\left(\frac{P e_{i}}{\Delta z}-z_{i} \frac{\Delta \overline{\psi_{N}}}{\Delta z}\right) z}-\frac{P e_{i}}{K_{i, c}\left(P e_{i}-z_{i} \Delta \overline{\psi_{N}}\right)} c_{i}\left(\Delta z^{+}\right)\left(e^{\left(\frac{P e_{i}}{\Delta z}-z_{i} \frac{\Delta \overline{\psi_{N}}}{\Delta z}\right) z}-1\right)
$$

At $\mathrm{z}=\Delta \mathrm{z}$, the concentration inside the pore is $\overline{c_{l}}\left(\Delta z^{-}\right)$:

$$
\overline{c_{l}}\left(\Delta z^{-}\right)=\overline{c_{l}}\left(0^{+}\right) e^{\left(P e_{i}-z_{i} \Delta \overline{\psi_{N}}\right)}-\frac{P e_{i}}{K_{i, c}\left(P e_{i}-z_{i} \Delta \overline{\psi_{N}}\right)} c_{i}\left(\Delta z^{+}\right)\left(e^{\left(P e_{i}-z_{i} \Delta \overline{\psi_{N}}\right)}-1\right)
$$

Considering the partition equations (7.1) and (7.2), we can express equation (A.3) usig only permeate and retentate concentrations:

$c_{i}\left(\Delta z^{+}\right) \Lambda_{i,\left(\Delta z^{-} \mid \Delta z^{+}\right)}=c_{i}\left(0^{-}\right) \Lambda_{i,\left(0^{-} \mid 0^{+}\right)} e^{\left(P e_{i}-z_{i} \Delta \overline{\psi_{N}}\right)}-\frac{P e_{i} c_{i}\left(\Delta z^{+}\right)}{K_{i, c}\left(P e_{i}-z_{i} \Delta \overline{\psi_{N}}\right)}\left(e^{\left(P e_{i}-z_{i} \Delta \overline{\psi_{N}}\right)}-1\right)$

Finally, algebraic manipulation of equation (A.4) yields: 


$$
\frac{c_{i}\left(\Delta z^{+}\right)}{c_{i}\left(0^{-}\right)}=\frac{\Lambda_{i,\left(0^{-} \mid 0^{+}\right)} K_{i, c}\left(P e_{i}-z_{i} \Delta \overline{\psi_{N}}\right) e^{\left(P e_{i}-z_{i} \Delta \overline{\psi_{N}}\right)}}{\Lambda_{i,\left(\Delta z^{-} \mid \Delta z^{+}\right)} K_{i, c}\left(P e_{i}-z_{i} \Delta \overline{\psi_{N}}\right)-P e_{i}\left(1-e^{\left(P e_{i}-z_{i} \Delta \overline{\psi_{N}}\right)}\right)}
$$

\section{References}

[1] E. Drioli, L. Giorno, Comprehensive membrane science and engineering: Volume 1, 1st ed., Elsevier Science, Kidlington, 2010.

[2] H. Yacubowicz, J. Yacubowicz, Nanofiltration: properties and uses, Filtr. Sep. 42 (2005) 16-21.

[3] A.I. Schäfer, A.G. Fane, T.D. Waite, Nanofiltration: Principles and Applications, 1st ed., Elsevier Science, Kidlington, 2005.

[4] R.J. Petersen, Composite reverse osmosis and nanofiltration membranes, J. Memb. Sci. 83 (1993) 81-150.

[5] N. Misdan, W.J. Lau, a. F. Ismail, T. Matsuura, D. Rana, Study on the thin film composite poly(piperazine-amide) nanofiltration membrane: Impacts of physicochemical properties of substrate on interfacial polymerization formation, Desalination. 344 (2014) 198-205.

[6] L. Hu, S. Zhang, R. Han, X. Jian, Preparation and performance of novel thermally stable polyamide/PPENK composite nanofiltration membranes, Appl. Surf. Sci. 258 (2012) 90479053.

[7] B. Mi, O. Coronell, B. Marinas, F. Watanabe, D. Cahill, I. Petrov, Physico-chemical characterization of NF / RO membrane active layers by Rutherford backscattering spectrometry, J. Memb. Sci. 282 (2006) 71-81.

[8] E. Idil Mouhoumed, a. Szymczyk, a. Schäfer, L. Paugam, Y.H. La, Physico-chemical characterization of polyamide NF/RO membranes: Insight from streaming current measurements, J. Memb. Sci. 461 (2014) 130-138.

[9] V. Freger, Nanoscale Heterogeneity of Polyamide Membranes Formed by Interfacial Polymerization, Langmuir. 19 (2003) 4791-4797.

[10] P.S. Singh, A.P. Rao, P. Ray, A. Bhattacharya, K. Singh, N.K. Saha, et al., Techniques for characterization of polyamide thin film composite membranes, Desalination. 282 (2011) 7886.

[11] F.A. Pacheco, I. Pinnau, M. Reinhard, J.O. Leckie, Characterization of isolated polyamide thin films of RO and NF membranes using novel TEM techniques, J. Memb. Sci. 358 (2010) 51-59. 
[12] A.H. Galama, J.W. Post, M.A. Cohen Stuart, P.M. Biesheuvel, Validity of the Boltzmann equation to describe Donnan equilibrium at the membrane-solution interface, J. Memb. Sci. 442 (2013) 131-139.

[13] M. Higa, A. Kira, A. Tanioka, K. Miyasaka, Ionic partition equilibrium in a charged membrane immersed in a mixed ionic solution, J. Chem. Soc. Faraday Trans. 89 (1993) 3433.

[14] D. Vezzani, S. Bandini, Donnan equilibrium and dielectric exclusion for characterization of nanofiltration membranes, Desalination. 149 (2002) 477-483.

[15] C. Labbez, P. Fievet, A. Szymczyk, A. Vidonne, A. Foissy, J. Pagetti, Retention of mineral salts by a polyamide nanofiltration membrane, Sep. Purif. Technol. 30 (2003) 47-55.

[16] W.R. Bowen, J.S. Welfoot, Modelling the performance of membrane nanofiltration - critical assessment and model development, Chem. Eng. Sci. 57 (2002) 1121-1137.

[17] W. Bowen, A. Mohammad, N. Hilal, Characterisation of nanofiltration membranes for predictive purposes-use of salts, uncharged solutes and atomic force microscopy, J. Memb. Sci. 126 (1997) 91-105.

[18] C. Labbez, P. Fievet, a Szymczyk, a Vidonne, a Foissy, J. Pagetti, Analysis of the salt retention of a titania membrane using the "DSPM" model: effect of $\mathrm{pH}$, salt concentration and nature, J. Memb. Sci. 208 (2002) 315-329.

[19] J. Schaep, C. Vandecasteele, A.W. Mohammad, W.R. Bowen, Analysis of the Salt Retention of Nanofiltration Membranes Using the Donnan-Steric Partitioning Pore Model, Sep. Sci. Technol. 34 (1999) 3009-3030.

[20] E. Glueckauf, Proceeding of the first international symposium on water desalination, Volume 1, in: Proceeding First Int. Symp. Water Desalin., Washington DC, 1967: p. 143.

[21] A.G. Fane, A.R. Awang, M. Bolko, R. Macoun, R. Schofield, Y.R. Shen, et al., Metal recovery from wastewater using membranes., Water Sci. Technol. 25 (1992) 5-18.

[22] A.E. Yaroshchuk, Dielectric exclusion of ions from membranes., Adv. Colloid Interface Sci. 85 (2000) 193-230.

[23] S. Bandini, D. Vezzani, Nanofiltration modeling: the role of dielectric exclusion in membrane characterization, Chem. Eng. Sci. 58 (2003) 3303-3326.

[24] W.R. Bowen, H. Mukhtar, Characterisation and prediction of separation performance of nanofiltration membranes, J. Memb. Sci. 112 (1996) 263-274.

[25] W.R. Bowen, A.W. Mohammad, Characterization and prediction of nanofiltration membrane performance-a general assessment, Trans. Inst. Chem. Eng. 76 (1998) 885-893.

[26] A. Szymczyk, P. Fievet, Investigating transport properties of nanofiltration membranes by means of a steric, electric and dielectric exclusion model, J. Memb. Sci. 252 (2005) 77-88.

[27] A.E. Yaroshchuk, Non-steric mechanisms of nanofiltration: superposition of Donnan and dielectric exclusion, Sep. Purif. Technol. 22-23 (2001) 143-158. 
[28] D.L. Oatley, L. Llenas, N.H.M. Aljohani, P.M. Williams, X. Martínez-Lladó, M. Rovira, et al., Investigation of the dielectric properties of nanofiltration membranes, Desalination. 315 (2013) 100-106.

[29] D.L. Oatley, L. Llenas, R. Pérez, P.M. Williams, X. Martínez-Lladó, M. Rovira, Review of the dielectric properties of nanofiltration membranes and verification of the single oriented layer approximation., Adv. Colloid Interface Sci. 173 (2012) 1-11.

[30] D.L. Oatley-Radcliffe, S.R. Williams, M.S. Barrow, P.M. Williams, Critical appraisal of current nanofiltration modelling strategies for seawater desalination and further insights on dielectric exclusion, Desalination. 343 (2014) 154-161.

[31] W.R. Bowen, J.S. Welfoot, Predictive modelling of nanofiltration: membrane specification and process optimisation, Desalination. 147 (2002) 197-203.

[32] R. Renou, A. Szymczyk, A. Ghoufi, Unravelling the Anomalous Dielectric Permittivity of Nanoconfined Electrolyte Solutions, Nanoscale. (2015) 6661-6666.

[33] R. Renou, A. Szymczyk, G. Maurin, P. Malfreyt, A. Ghoufi, Superpermittivity of nanoconfined water, J. Chem. Phys. 142 (2015) 184706.

[34] R. Renou, a. Szymczyk, a. Ghoufi, Tunable dielectric constant of water at the nanoscale, Phys. Rev. E. 91 (2015) 032411.

[35] A. Ghoufi, A. Szymczyk, R. Renou, M. Ding, Calculation of local dielectric permittivity of confined liquids from spatial dipolar correlations, EPL (Europhysics Lett. 99 (2012) 37008.

[36] B. Saliha, F. Patrick, S. Anthony, Investigating nanofiltration of multi-ionic solutions using the steric, electric and dielectric exclusion model, Chem. Eng. Sci. 64 (2009) 3789-3798.

[37] T.-Y. Liu, H.-G. Yuan, Q. Li, Y.-H. Tang, Q. Zhang, W. Qian, et al., Ion-Responsive Channels of Zwitterion-Carbon Nanotube Membrane for Rapid Water Permeation and Ultrahigh Mono/Multivalent Ion Selectivity., ACS Nano. 9 (2015) 7488-96.

[38] R.C. Weast, ed., CRC Handbook of Chemistry, CRC Press, Boca Raton, FL, 1980.

[39] J. Palmeri, P. Blanc, A. Larbot, P. David, Theory of pressure-driven transport of neutral solutes and ions in porous ceramic nanofiltration membranes, J. Memb. Sci. 160 (1999) 141-170.

[40] X.-L. Wang, T. Tsuru, S. Nakao, S. Kimura, The electrostatic and steric-hindrance model for the transport of charged solutes through nanofiltration membranes, J. Memb. Sci. 135 (1997) 1932.

[41] X. Lefebvre, J. Palmeri, P. David, Nanofiltration Theory: An Analytic Approach for Single Salts, J. Phys. Chem. B. 108 (2004) 16811-16824.

[42] A. Szymczyk, M. Sbaï, P. Fievet, A. Vidonne, Transport properties and electrokinetic characterization of an amphoteric nanofilter., Langmuir. 22 (2006) 3910-3019.

[43] X. Lefebvre, J. Palmeri, Nanofiltration theory: good co-ion exclusion approximation for single salts., J. Phys. Chem. B. 109 (2005) 5525-5540. 
[44] G. Hagmeyer, R. Gimbel, Modelling the salt rejection of nanofiltration membranes for ternary ion mixtures and for single salts at different pH values, Desalination. 117 (1998) 247-256.

[45] J. Garcia-Aleman, Experimental analysis, modeling, and theoretical design of McMaster porefilled nanofiltration membranes, J. Memb. Sci. 240 (2004) 237-255.

[46] P. Ramírez, V. Gómez, J. Cervera, B. Schiedt, S. Mafé, Ion transport and selectivity in nanopores with spatially inhomogeneous fixed charge distributions., J. Chem. Phys. 126 (2007) 194703.

[47] W.B.S. de Lint, P.M. Biesheuvel, H. Verweij, Application of the charge regulation model to transport of ions through hydrophilic membranes: one-dimensional transport model for narrow pores (nanofiltration)., J. Colloid Interface Sci. 251 (2002) 131-142.

[48] A. Plecis, R.B. Schoch, P. Renaud, Ionic Transport Phenomena in Nanofluidics: Experimental and Theoretical Study of the Exclusion-Enrichment Effect on a Chip, Nano Lett. 5 (2005) 11471155.

[49] P.M. Bungay, H. Brenner, The motion of a closely-fitting sphere in a fluid-filled tube, Int. J. Multiph. Flow. 1 (1973) 25-56.

[50] A. Szymczyk, H. Zhu, B. Balannec, Ion rejection properties of nanopores with bipolar fixed charge distributions, J. Phys. Chem. B. 114 (2010) 10143-10150.

[51] H. Zhu, A. Szymczyk, B. Balannec, On the salt rejection properties of nanofiltration polyamide membranes formed by interfacial polymerization, J. Memb. Sci. 379 (2011) 215-223.

[52] H. Zhu, Multiscale modelling of transfer mechanisms through nanofiltration membranes, Université de Rennes 1, 2011.

[53] S. Déon, A. Escoda, P. Fievet, A transport model considering charge adsorption inside pores to describe salts rejection by nanofiltration membranes, Chem. Eng. Sci. 66 (2011) 2823-2832.

[54] J. Schaep, C. Vandecasteele, A.W. Mohammad, W.R. Bowen, Modelling the retention of ionic components for different nanofiltration membranes, Sep. Purif. Technol. 22-23 (2001) 169179.

[55] M. Born, Volumen und Hydratationswärme der lonen, Zeitschrift Für Phys. 1 (1920) 45-48.

[56] A.A. Rashin, B. Honig, Reevaluation of the Born Model of Ion Hydration, J. Phys. Chem. 89 (1985) 5588-5593.

[57] G. Hagmeyer, R. Gimbel, Modelling the salt rejection of nanofiltration membranes for ternary ion mixtures and for single salts at different pH values, Desalination. 117 (1998) 247-256.

[58] W.B.S. de Lint, Transport of electrolytes through ceramic nanofiltration membranes, Twente University, 2003.

[59] Y. Zhao, Y. Zhang, W. Xing, N. Xu, Influences of $\mathrm{pH}$ and ionic strength on ceramic microfiltration of TiO2 suspensions, Desalination. 177 (2005) 59-68. 
[60] J. Palmeri, J. Sandeaux, R. Sandeaux, X. Lefebvre, P. David, C. Guizard, et al., Modeling of multi-electrolyte transport in charged ceramic and organic nanofilters using the computer simulation program NanoFlux, Desalination. 147 (2002) 231-236.

[61] A.W. Mohammad, Y.H. Teow, W.L. Ang, Y.T. Chung, D.L. Oatley-Radcliffe, N. Hilal, Nanofiltration membranes review: Recent advances and future prospects, Desalination. 356 (2014) 226-254.

[62] N. Hilal, M. Al-Abri, H. Al-Hinai, M. Abu-Arabi, Characterization and retention of NF membranes using PEG, HS and polyelectrolytes, Desalination. 221 (2008) 284-293.

[63] A. Pérez-González, R. Ibáñez, P. Gómez, A.M. Urtiaga, I. Ortiz, J. a. Irabien, Nanofiltration separation of polyvalent and monovalent anions in desalination brines, J. Memb. Sci. 473 (2015) 16-27.

[64] L.D. Nghiem, S. Hawkes, Effects of membrane fouling on the nanofiltration of pharmaceutically active compounds (PhACs): Mechanisms and role of membrane pore size, Sep. Purif. Technol. 57 (2007) 176-184.

[65] Y.-L. Lin, P.-C. Chiang, E.-E. Chang, Removal of small trihalomethane precursors from aqueous solution by nanofiltration., J. Hazard. Mater. 146 (2007) 20-9.

[66] a. W. Mohammad, N. Hilal, H. Al-Zoubi, N. a. Darwish, Prediction of permeate fluxes and rejections of highly concentrated salts in nanofiltration membranes, J. Memb. Sci. 289 (2007) 40-50.

[67] C.-J. Lin, S. Shirazi, P. Rao, Mechanistic Model for Fouling on Nanofiltration Membrane, J. Environ. Eng. 131 (2005) 1387-1392. 


\section{Highlights}

-We show that the evolution of the transmembrane potential with the concentration

-Using pore averaged potential gradient, the SEDE model is simplified

-Good agreement is obtained between the simplified and the original model

-Computation time is greatly reduced

-Good agreement with experimental data for moderate to high concentrations 